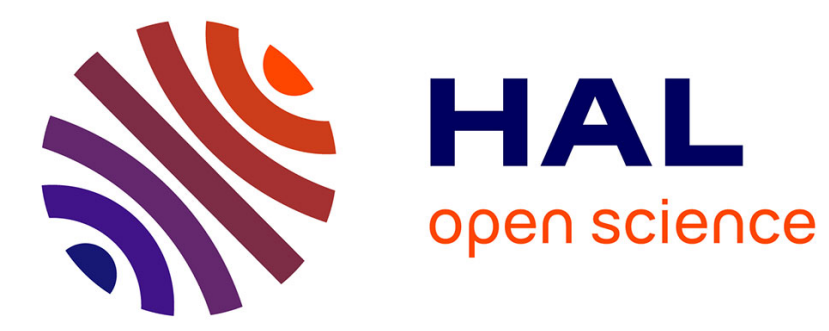

\title{
New material of Diacodexis (Mammalia, Artiodactyla) from the early Eocene of Southern Europe
}

Myriam Boivin, Maeva Orliac, Miguel Antunes Telles, Marc Godinot, Yves Laurent, Bernard Marandat, Dominique Vidalenc, Rodolphe Tabuce

\section{- To cite this version:}

Myriam Boivin, Maeva Orliac, Miguel Antunes Telles, Marc Godinot, Yves Laurent, et al.. New material of Diacodexis (Mammalia, Artiodactyla) from the early Eocene of Southern Europe. Geobios, 2018, 51 (4), pp.285-306. 10.1016/j.geobios.2018.06.003 . hal-03052875

\section{HAL Id: hal-03052875 \\ https://hal.science/hal-03052875}

Submitted on 10 Dec 2020

HAL is a multi-disciplinary open access archive for the deposit and dissemination of scientific research documents, whether they are published or not. The documents may come from teaching and research institutions in France or abroad, or from public or private research centers.
L'archive ouverte pluridisciplinaire $\mathbf{H A L}$, est destinée au dépôt et à la diffusion de documents scientifiques de niveau recherche, publiés ou non, émanant des établissements d'enseignement et de recherche français ou étrangers, des laboratoires publics ou privés. 


\section{New material of Diacodexis (Mammalia, Artiodactyla) from the early}

\section{Eocene of Southern Europe}

3

4 Boivin Myriam ${ }^{\text {a }}$, Orliac Maëva J. ${ }^{\text {a,* }}$, Antunes Telles Miguel ${ }^{\text {b }}$, Godinot Marc ${ }^{\text {c }}$, Laurent

5 Yves ${ }^{\text {d,e }}$, Marandat Bernard ${ }^{\text {a }}$, Vidalenc Dominique ${ }^{\mathrm{f}}$, Tabuce Rodolphe ${ }^{\text {a }}$

6

7 a Institut des Sciences de l'Évolution de Montpellier, c.c. 064, Université de Montpellier,

CNRS, IRD, EPHE, place Eugène Bataillon, F-34095 Montpellier Cedex 05, France

9

b Academia das Ciencias de Lisboa, 19 Rua da Academia das Ciências, 1249-122 Lisbon,

Portugal

${ }^{c}$ EPHE, PSL, et Sorbonne Universités - CR2P - MNHN, CNRS, UPMC-Paris 6

${ }^{\text {d }}$ Muséum d'Histoire Naturelle de Toulouse, 35 allée Jules Guesde, F-31000 Toulouse, France 16

${ }^{\mathrm{e}}$ Association Paléontologique du Sud-Ouest, 13 chemin des Telles, F-31360 Roquefort-sur-

${ }^{\mathrm{f}} 103$ avenue F. Mitterrand, 31800, St Gaudens, France

* Corresponding author. E-mail address: maeva.orliac@umontpellier.fr (M.J. Orliac). 


\section{Abstract}

Diacodexeidae are the first representatives of Artiodactyla in the fossil record. Their first occurrence is at the very base of the Ypresian (earliest Eocene, 56.0 Ma) with the genus Diacodexis. Diacodexis is a well-diversified genus during the early Eocene in Europe, especially during the MP7-MP8+9 interval. However, most of European species are documented by scarce material, retrieved from single localities. In this work, we describe new Diacodexis material from MP7 and MP8+9 localities of Southern Europe including material of $D$. antunesi from Silveirinha, considered as the most primitive European Diacodexis, and material from three localities from Southern France (Fordones, Palette, and La Borie). The new material documents Diacodexis premolar morphology and deciduous dentition which bear potentially important phylogenetic information, as well as astragali, including a specimen from Silveirinha that constitutes the earliest occurence of an astragalus of the genus Diacodexis in the European fossil record. Investigation of the enamel microstructure reveals that early European species had a simple enamel pattern with onelayered Schmelzmuster composed of 'basic' radial enamel only, instead of the two-layered Schmelzmuster (thin radial enamel + thick layer of Hunter-Schreger bands) observed on North American species and so far considered to represent the primitive condition within Artiodactyla. In accordance with previous studies, our observations highlight that Diacodexis gigasei from Belgium is morphologically closer to the North American species D. ilicis than to $D$. antunesi from Portugal. The latter species, together with $D$. aff. antunesi from Fordones, appears to be morphologically closer to the Asiatic taxa D. indicus and D. pakistanensis. Finally, we found numerous similarities between $D$. cf. gigasei from Palette and D. gigasei, a result that challenges the intra-European provincialism that characterizes the earliest Ypresian. Diacodexis gigasei could be one of the rare species in common between northwestern and southwestern bioprovinces. 
51 Keywords:

52 Diacodexeidae

53 Ypresian

54 Enamel microstructure

55 Deciduous dentition

56 Astragalus

57

58 


\section{Introduction}

Diacodexeid artiodactyls are the first representatives of even toed hoofed mammals in the fossil record (Rose, 1982, 2006; Theodor et al., 2007). Their first occurrence is found at the very base of the Ypresian (earliest Eocene, 56.0 million years ago) with the genus Diacodexis Cope, 1882. Based on this early occurrence in the fossil record and on their very simple tribosphenic molar pattern, Diacodexeidae have been regarded as primitive among Artiodactyla (Cope, 1882; Romer, 1966; Van Valen, 1971; Godinot, 1981; Theodor et al., 2007). Formal phylogenetic analyses show Diacodexis as the first offshoot of the order (Geisler and Theodor, 2009) or close to the differentiation of crown artiodactyl groups (Gentry and Hooker, 1988; Geisler, 2001; Orliac and Ducrocq, 2012; Gatesy et al., 2012). Together with other modern groups of mammals such as primates or perissodactyls, Diacodexis makes its first appearance in the fossil record during the Mammalian Dispersal Event (MDE), which coincides with the global climate warming of the Paleocene Eocene Thermal Maximum (or PETM) characterized by a global negative carbon isotope excursion (CIE) (Magioncalda et al., 2004; Gingerich, 2006). Species of Diacodexis have been reported from Eocene fossil localities on all continents of the Northern hemisphere, and dental, cranial and postcranial features of the genus are now well documented (e.g., Guthrie, 1971; Godinot, 1981; Russell et al., 1983; Sigogneau-Russell and Russell, 1983; Sudre et al., 1983; Thewissen et al., 1983; Kumar and Jolly, 1986; Gingerich, 1989; Smith et al. 1996; Bajpai et al., 2005; Kumar et al., 2010; Orliac and Gilissen, 2012; Orliac and O’Leary, 2014).

Diacodexis is known from Asia, Europe, and North America, three places that have been alternatively proposed as center of origin of the genus (Thewissen et al., 1983; Krishtalka and Stucky, 1985; Smith et al., 1996). Europe and North America have housed, among others, the oldest Diacodexis (earliest Eocene) whereas the first occurrence of the genus in Asia is a little more recent (early Eocene; Kumar et al., 2010). The oldest North American species is $D$. 
ilicis from Wasatchian-Meniscotherium (Wa-M) and Wasatchian-0 (Wa-0) biozones of the Wasatchian NALMA (North American Land Mammal Age) (Gingerich, 1989; Rose et al., 2012:92); Wa-M and and Wa-0 faunas are, respectively, coincident with the maximum of the CIE and the main body of the PETM (Bowen et al., 2014).

In Europe, the first occurrence of Diacodexis also coincides with the onset of the PETM with D. gigasei from Dormaal (MP7 Reference Level) and Erquelinnes, Belgium (Smith et al., 1996; Smith et al., 2006; Missiaen et al., 2013) (Fig. 1). Other MP7 species are D. antunesi from Silveirinha, Portugal (Estravis and Russell, 1989), Diacodexis sp. from Le Quesnoy, France (Nel et al., 1999), D. morrisi from Abbey Wood, UK (Hooker, 2010), Diacodexis sp. from Kyson, UK (Sudre et al., 1983), D. gazini from Rians, France (Godinot, 1981), and Diacodexis cf. gazini from Fordones, France (Marandat, 1991). Among these species, Estravis and Russell (1989) and Theodor et al. (2007) considered D. antunesi as the oldest, most primitive European Diacodexis. Later in the early Eocene, Diacodexis is known by two species: $D$. corsaensis from the MP8+9 locality of Corsà 0, Spain (Checa Soler, 2004) and D. varleti from several localities from the Paris Basin such as Condé-en-Brie, Mutigny, Avenay (MP8+9 Reference Level), and Pourcy (either MP7 or MP8+9) (Sudre et al., 1983) (Fig. 1). A closely related species, named $D$. cf. varleti was described from several MP 10 localities also from the Paris Basin (Saint-Agnan, Cuis, Mancy, Prémontré, and Grauves) (Sudre et al., 1983; Sudre and Erfurt, 1996). The latest occurrence of Diacodexis cf. varleti dates from the "untere Unterkohle" (MP11) of the Geiseltal, Germany (Erfurt and Sudre, 1996) (Fig. 1). Finally, several Diacodexis sp. indet. were mentioned from numerous localities from Spain, correlated with MP10 (Sudre et al., 1983; Antunes et al., 1997) Diacodexis is therefore a well-diversified genus during the early Eocene in Europe, especially during the MP7-MP8+9 interval. However, most of European Diacodexis species are documented by scarce material, retrieved from a single locality. The scarcity of the 
material often prevents comparing the same dental loci from two localities. Indeed, some localities yielded upper dentition only, while others yielded lower dentition. Besides, the lack of complete tooth rows makes dental association tricky. Finally, the scarcity of the documented material makes it difficult to apprehend the potential intraspecific variability that exists within Diacodexis species.

Here, we describe new material from MP7 and MP8+9 localities of Southern Europe that greatly increases our knowledge of European Diacodexis species. The new material comes from Portugal (Silveirinha), and Southern France (Fordones, Palette, and La Borie) and notably includes a mandible with p3-m3 and an upper cheek tooth row with P3M3, which represents the most complete Diacodexis remains in Europe to date. The new material described also documents Diacodexis premolar morphology and deciduous dentition which bear potentially important phylogenetic information, as well as one astragalus from Silveirinha that constitutes the earliest mention of an astragalus of the genus Diacodexis in the European fossil record. The enamel microstructure of Diacodexis species from Silveirinha and Fordones is also investigated. These new data about European early Diacodexis species call into questions features considered as primitive within Artiodactyla, and allow discussion of the distribution and palaeobiogeographic relationships between Northern and Southern Europe near MP7.

\section{Material and methods}

\subsection{Material}

\subsubsection{New material}

The material studied here comes from four localities, one is situated in Portugal (Silveirinha), the others in Southern France (Fordones, Palette, and La Borie) (Fig. 1). Silveirinha, Palette, and La Borie are well-known for having yielded rich mammalian faunas, 
the most diversified ones for the early-middle Ypresian period of Southern Europe (e.g., Antunes and Russell, 1981; Antunes et al., 1987; Estravis, 2000; Tabuce et al., 2006, 2009, 2011 for Silveirinha; Godinot, 1984; Godinot et al., 1987; Solé et al., 2017 for Palette; and Laurent et al., 2010; Robinet et al., 2015; Solé et al., 2014 for La Borie). According to the Southern Europe biochronological sequence proposed recently for the beginning of the Eocene (Marandat et al., 2012), Silveirinha would be the oldest Southern European site referred to the MP7 level and Fordones and Palette -also referred to the MP7- would be coeval and slightly younger than Silveirinha. Interestingly, Fordones and Palette are considered equivalent in age with another Southern French locality (Le Clot); the latter being estimated 1 myr younger than the MP7 reference Dormaal locality (Yans et al., 2014). Finally, as for the locality of La Borie, Laurent et al. (2010) argued for a MP8+9 age. The mandible PAT 159 from Palette was scanned at the CT-Scan facility of the Montpellier University with a resolution of $35 \mu \mathrm{m}$ and 3D models representing its external surface and a virtual restoration of its ascending ramus are available on MorphoMuseuM (Orliac et al., in press, Models ID: M3\#315_UMPAT159, M3\#317_UMPAT159).

\subsubsection{Comparison material}

Comparisons are performed with Diacodexis species from Europe, Asia and North America. Observation of the European species are based on D. antunesi Estravis and Russell, 1989 from Silveirinha, Portugal (direct observation of new material and on casts of the material figured by Estravis and Russell, 1989); D. gigasei Smith, Smith and Sudre, 1996 from Dormaal, Belgium (direct observation on casts of the material); D. morrisi Hooker, 2010 from Abbey Wood, England (observation from Hooker 2010: fig. 47 and direct observation on casts of M15141); D. varleti Sudre, Russell, Louis and Savage, 1983 from Condé-en-Brie, France (direct observation of the original material stored at the MNHN); D. gazini Godinot, 
1981 from Rians, France (direct observation of the original material stored at the MNHN); $D$. corsaensis Checa Soler, 2004 from Corsà 0 (observation from Checa Soler, 2004: fig. 2). Observations of the Asian species are based on Diacodexis pakistanensis Thewissen et al., 1983 (= Gujaratia pakistanensis, see Kumar et al. 2010 p.1249) (known from several localities in India and Pakistan); D. indicus (Bajpai et al., 2005) (Vastan, India), D. parvus Kumar et al., 2010 (Vastan, India), and Diacodexis sp. from Andarak 2, Kyrgyzstan (based on Thewissen et al., 1983; Kumar et al., 2010; and Averianov, 1996 respectively). Finally, observations of the North American species D. ilicis Gingerich, 1989 (Bighorn Basin, Wyoming, USA) and D. secans primus Krishtalka and Stucky, 1985 (Bighorn and Powder River Basin, Wyoming and Four Mile area, Colorado, USA) are based on Gingerich (1989) and Rose et al. (2012), and Krishtalka and Stucky (1985) respectively.

\subsection{Methods}

\subsubsection{Enamel microstructure}

We studied the enamel microstructure of two Diacodexis specimens: one $\mathrm{m} 2$ from Silveirhina (SNC 3) and one fragmentary upper molar from Fordones (FDN 254). Sample preparation followed the protocol of Tabuce et al. (2007a). Casts of the specimens were made prior to preparation for enamel microstructure study. All specimens were embedded in epoxy resin and sectioned horizontally and tangentially. We subsequently performed $37 \%$ phosphoric acid etching of the samples for 30 seconds to make the microstructural details visible. After rinsing with distilled water and drying, the samples were coated with conductive material (gold-palladium). They were observed and studied with two different scanning electron microscopes (SEM): HITACHI S4000 and S4800 (x250 to x500). Several parameters were evaluated in the description of enamel microstructure. Enamel thickness was measured perpendicularely to the Enamel-Dentine Junction (EDJ), and corresponds to the distance 
between that plane and the Enamel Outer Surface (EOS). The orientation of the interprismatic matrix (IPM) is the angle between crystallites of the IPM and those of prisms. Each measure has been reproduced ten times.

\subsubsection{Abbreviations for institutions and dental nomenclature followed}

Institutions: CEPUNL, Centro de Estratigrafia e Paleobiologia da Universidade Nova de Lisboa; MHNT, Muséum d'Histoire Naturelle de Toulouse, Toulouse, France; MNHN, Muséum National d'Histoire Naturelle, Paris, France; UCMP, University of California Museum of Paleontology, Berkeley, USA; UM, Université de Montpellier, Montpellier, France.

The dental nomenclature mainly follows Boisserie et al. (2009) and Orliac and Ducrocq (2012).

\section{Systematic paleontology}

Order Artiodactyla Owen, 1848

Superfamily Dichobunoidea Gill, 1872

Family Diacodexeidae Gazin, 1955

Genus Diacodexis Cope, 1882

\subsection{New material from the locality of Silveirinha Pequena, Baixo Mondego, Portugal}

The first mention of Diacodexis remains from the early Eocene locality of Silveirinha was made in the faunal list of the locality provided by Antunes and Russell (1981: p. 1101) as Diacodexis cf. gazini. Estravis and Russell (1989) subsequently revised the material and erected a new species, Diacodexis antunesi Estravis and Russell, 1989. In the latter work, 
abundant dental remains of $D$. antunesi are described, documenting upper and lower molars, as well as $\mathrm{dP} 4$ and $\mathrm{p} 2$ or $\mathrm{p} 3$ of the species. Part of this Diacodexis material is also described and figured in the $\mathrm{PhD}$ thesis of Estravis (1992: p. 182-196). Additional material described here comes from field campaigns conducted in Silveirinha in the past 20 years.

Diacodexis antunesi Estravis and Russell, 1989

Fig. 2

Synonymy: 1981. D. cf. gazini - Antunes and Russell, p. 1101.

Holotype: r. m2 SV3 338 (coll. CEPUNL, in Estravis and Russell, 1989: pl. 1, fig. 2).

Material (coll. CEPUNL): in addition to that published by Estravis and Russell (1989) - SNC 64, dp2 or dp3 (left); SNC 386, p2 or p3 (left); SNC 74, m1-2 (right); SNC 6, m1 (right); SNC 93, m1 (right); SNC 3, m2 (right); SNC 17, m3 (left); SNC 59, m3 (left); SNC 63, m3 (right); SNC 65, m3 (left); SNC 58, P3 (right); SNC 33, P4 (right); SNC 311, P4 (right); SNC 405, P4 (right); SNC 13, dP4 (left); SNC 49, M1 (right); SNC 339, M1 (right); SNC 20, M2 (right); SNC 25, M2 (right); SNC 36, M2 (right); SNC 55, M2 (left); SNC 95, M3 (right); SNC 18, M3 (right); SNC 262, M3 (right); SNC 687, astragalus (right).

Type locality and horizon: Silveirinha Pequena, Baixo Mondego, Portugal; Silveirinha Formation, Rio Mondego Member, early Eocene, $\sim \mathrm{MP7}$.

Original diagnosis: see Estravis and Russell (1989 : p. 31).

Emended diagnosis: very small species of Diacodexis with high and sharp cusps and cuspids; long and well-marked crests; lower molars with central and low cristid obliqua; hypoconulid small and close to entoconid on m1-2; short or absent labial cingulid; P3 with small lingual lobe; P4 with strong preprotocristid, connected to the antero-labial corner of the tooth, labial margin without ectoflexus; M1-2 with large parastyle protruding anteriorly; lingual lobe of M1-2 clearly slenderer antero-posteriorly than the labial margin of the crown; 
M3 triangular in shape compared to M2.

Measurements: Tables 1-2.

\section{Description:}

Lower dentition. Two lower premolars (SNC 64 and SNC 386) have been identified in addition to the deciduous premolar published by Estravis and Russell (1989: pl. 2.7) (Fig. 2(A-D)). Both specimens present a low crown. The paraconid is lingually located and distinct

from the preprotocristid. The hypoconid is separated from the postprotocristid by a small groove; in labial and lingual views, the hypoconid lies below the level of the paraconid. Based on the very small enamel thickness and on its low, labio-lingually narrow crown, SNC 64 is referred to as dp2 or a dp3. SNC 386 has a thicker enamel and a wider protoconid than SNC 64 and rather documents permanent dentition, $\mathrm{p} 2$ or $\mathrm{p} 3$.

The new sample includes nine lower molars of $D$. antunesi. As noted by Estravis and Russell (1989), m1 has a large paraconid separated from the metaconid whereas this cuspid is clearly smaller on $\mathrm{m} 2$ (Fig. 2(M)). This character, together with the size of the tooth, allows for the m1-2 distinction. The trigonid becomes wider and the entoconid increases in both width and height from $\mathrm{m} 1$ to $\mathrm{m} 3$. The lower molars of $D$. antunesi present a trigonid with high and pointed cusps. Protoconid and metaconid are of sub-equal height, edges of the trigonid are defined by the preprotocristid and postprotocristid labially, by the postmetacristid, premetacristid, postparacristid lingually, and by the preparacristid anteriorly. The basin of the trigonid is deep; an endometafossid is observed on unworn teeth, as well as a clear postmetafossid. The basin of the talonid is delimited labially by a low cristid obliqua (=prehypocristid). Lingually, the ectoentocristid is short and low and connects a very slight postectometacristid. The postectometacristid is variably absent or very slight in the new sample, a character also observed on the material published by Estravis and Russell (1989). The anterior end of the low cristid obliqua occupies a central position on all lower molars of 
our sample: it reaches anteriorly the level of the trigonid notch. On m1-2, the hypoconulid is connected to the entoconid, to the hypoconid and to a long posterior cingulid by high cristids. The hypoconulid is closely apposed to the entoconid. The labial cingulid is short or absent on $\mathrm{m} 1-2$. Despite important variations concerning the posterior lobe of $\mathrm{m} 3$, in all specimens, the hypoconulid is clearly distinct from the talonid on $\mathrm{m} 3$ and a deep groove separates the hypoconulid from the entoconid. A small accessory cusp, labial to the hypoconulid, can occur (Fig. 2(J)).

Upper dentition. The new sample includes five upper premolars, including a decidual one. Two new premolar loci are documented here in addition to the $\mathrm{dP} 4$ already described by Estravis and Russell (1989). SNC 58 is broken in its lingual part but its shape indicates a P3 (Fig. 2(S)). Its parastyle is reduced and embedded in the anterior cingulum. The posterior part of the tooth is occupied by a large metastyle. The lingual portion of the tooth is broken and the extension of the lingual lobe cannot be assessed. The P4 is subtriangular in occlusal view (Fig. 2(R)). The protocone is located slightly anterior to the paracone. The paracone is considerably larger and higher than the protocone and bears three cristae, a preparacrista and a postparacrista connected to a large parastyle and a smaller metastyle respectively, plus a clear and sharp endoparacrista, located low in the valley between the paracone and protocone. On both P4 specimens (SNC 405 and SNC 311), the endoparacrista connects to a very small endoprotocrista. The protocone shows a sharp preprotocrista merging anteriorly with the anterior cingulum; there is no postprotocrista. The parastyle is large especially on SNC 311 illustrated in Figure 2(R). There is no ectoflexus. The lingual, anterior and posterior cingula are continuous. The dP4 (SNC 13, Fig. 2(T)) is morphologically very close to that described by Estravis and Russell (1989: pl. 2.5). The tooth is posterolabially elongated, especially in its disto-labial corner. This character, together with its small width (Table 1), indicate that it is a deciduous tooth. DP4 morphology is very close to that of permanent upper molars. The 
protocone is big and low, and bears two thick cristae, the preprotocrista and the postprotocrista. They project toward the protoconule and the metaconule respectively but are separated from the latter by grooves. The metaconule and the protoconule are small and pointed. The metaconule bears three cristae: small pre and endometacristule, and a longer postmetacristule, which joins the metastyle at the disto-labial corner of the tooth. The endometacristule connects a small endometacrista, at the base of the metacone. Likewise, the protoconule bears a preprotocristule which joins the parastyle; yet, the endoprotocristule is lacking.

The M1-2 have a rather characteristic morphology (Fig. 2(P-Q)). The cusps are sharp and high, with well-marked cristae. The parastyle is large and projects/protrudes on the anterior edge of the tooth. A pericone is sometimes present (SNC 20, 55 and 74), a small hypocone is observed on some specimens (SNC 25 and 74). The preparacrista and postmetacrista are sharp, often both on the same plane as the centrocrista. The paraconule and the metaconule both present pre-, endo- and postcristae. The endopara and endometacristules connect the endopara and endometacrista respectively. The anterior and posterior cingula are long, thick, but never connect lingually. In occlusal view, the posterior edge of the crown shows an internal angle at the point where the postmetacristule joins the postero-labial corner of the tooth. The labial edge is straight except on the M2 SNC 20. The M1 SNC 49 differs from the other molars collected at Silveirinha by a weak parastyle, weak cingula, and a round shape at the base of the metacone and paracone. However, these observations could be due to a particular taphonomic history. Indeed, the enamel is thin or absent on the labial part of the tooth. The latter could have been digested by a predator. The M3s show a triangular outline. The three M3 of the new sample (SNC 18, SNC 75, and SNC 262) have a more rounded lingual outline than the specimen figured by Estravis and Russell (1989: pl. 2.1; SV3 126). M3s show a crest pattern similar to that of M1-2. 

variability. Variation on lower molars is observed on the length of the cingulids, the presence of the labial cingulid, and the connections of the posterior cristids of the talonid of the $\mathrm{m} 3$ (Estravis and Russell, 1989). Among the molar sample, variation on the paraconid size is also observed with the m3 SNC 17, which has a smaller paraconid. We interpret these differences as part of the plausible intraspecific variation. Indeed, the case of one specimen with a reduced paraconid within a Diacodexis sample has already been reported from other localities (Sudre et al., 1983; Kumar et al., 2010). All the material from Silveirinha is referred here to the species $D$. antunesi.

Enamel microstructure. The lower molar SNC 3 presents a 'basic' radial enamel on the whole enamel thickness (Fig. 3). Its thickness varies from 37 to $152 \mu \mathrm{m}$, its average is $91 \mu \mathrm{m}$. There is no synchronous prism undulation. The prisms have an average diameter of $4 \mu \mathrm{m}$. outer aprismatic part represents on average $4.5 \%$ of the enamel thickness.

Astragalus. In addition to the new dental material, one astragalus was also found at Silveirhina and constitutes the first mention of postcranial remains attributed to Diacodexis facet and the distal trochlea is missing. The two crests of the tibial trochlea are separated by a deep groove. They are asymmetric, the lateral condyle being higher than the medial one. There is no fossa for the anterior process of the tibia. The fossa for the tibial malleolus is wide and deep. The fibular sulcus is well marked in posterior view. The sustentacular facet is long, ovoid and its long axis is directed slightly proximomedially. The sustentacular facet is only slightly convex laterally. The ectal facet, separated from the sustentacular facet by a wide sulcus tali, is shrunk in its central part but more extended in its upper half. 


\section{Remarks:}

Comparison with MP7 and MP8+9 Southern European species. Diacodexis antunesi differs from most other species of the genus by its smaller size, especially for the lower molars (Figs. 4-5). Compared to D. gazini from the slightly more recent locality of Rians (Marandat et al., 2012), D. antunesi shows less massive upper and lower molars, with deeper labial notches in occlusal view between the trigonid and the talonid on lower molars and between the labial and lingual cusps on the upper molars. $D$. antunesi has smaller entoconid and hypoconid on lower molars (Fig. 6). On upper molars, the parastyle of D. antunesi is larger and protrudes anteriorly; on M1-2, the postmetacristule and preprotocristule are salient which confers to the crown an hourglass shape, something not observed on D. gazini which crown is more rectangular; when present, the hypocone of $D$. antunesi is smaller than that of D. gazini on M1-2. D. antunesi seems to show a close morphology to the poorly illustrated $D$. corsaensis from the MP8+9 locality of Corsà 0, Spain (Checa Soler, 2004: fig. 2), represented by lower dentition only. All dental remains of $D$. corsaensis are of larger size than $D$. antunesi (Fig. 4).

Comparison with MP7 Northern European species. Lower molars of D. antunesi differ from those of $D$. gigasei from Dormaal (Belgium) in having a smaller paraconid (especially on $\mathrm{m} 1$ ), a lower cristid obliqua on m1-2, a hypoconulid on m1-2 situated closer to the entoconid. The fresh lower molars of D. gigase i show a distinct endohypocristid (Fig. 6). The upper molars of D. antunesi and D. gigasei are close morphologically, but the parastyle is bigger in $D$. antunesi. They are also close regarding M3 proportions (Fig. 5). The P4 of $D$. gigasei presents an ectoflexus that is not present in the specimens of D. antunesi (Fig. 7(K)). The first lower molar of Diacodexis antunesi differs from that of D. morrisi (from MP7 of England) by a narrower talonid, and a lower and more central cristid obliqua. The upper molars of $D$. morrisi are more rounded lingually, and present a smaller parastyle; the groove 
intersecting the postprotocrista is deeper in D. morrisi (Fig. 7(G)). Despite a smaller size, D. antunesi is morphologically very close to $D$. varleti. Both species present a hypoconulid of m1-2 situated close to the entoconid, a protoconid almost as high as the metaconid on lower molars, hourglass-shaped upper M1-2 with salient postmetacristule. Morphological differences consist in a smaller parastyle of the upper molars less protruding anteriorly for $D$. varleti; M3s of the latter species also have a greater anteroposterior length (Fig. 5). Comparison with Northern American species. Diacodexis antunesi differs from $D$. ilicis from the Wasatchian of North America in having more pointed cuspids/cusps. The lower molars of North American species have a paraconid located more lingually. In D. antunesi, the hypoconulid of m1-2 is situated closer to the entoconid. On upper premolars, the paracone of P3 of D. antunesi is larger than that of D. ilicis and it does not seem to present the accessory cusp on the postparacrista observed in D. ilicis (Rose et al., 2012: fig. 51.D). The protocone lobe of $\mathrm{P} 3$ seems to be less distinct in $D$. antunesi (broken on the only available specimen). The $\mathrm{P} 4$ of $D$. antunesi presents a straight posterior edge, whereas $D$. ilicis shows an anterior deflection of the lingual part of the crown. The upper molars of D. antunesi and $D$. ilicis are close morphologically with an angular lingual lobe, sharp and salient preprotocristule and postmetacristule, and a parastyle protruding anteriorly. Based on what is preserved of the astragalus, the sustentacular facet seems to be larger in $D$. antunesi than in $D$. ilicis.

\section{Comparison with Asian species. Diacodexis antunesi differs from D. indicus in being} smaller and in having a wider sulcus tali, a very long and posterolabially expanded postmetacrista on $\mathrm{dP} 4$, more transverse upper molars with stronger parastyle and metastyle, and more posteriorly deflected postprotocrista on M2; its lower molars have a less elevated and a more labial cristid obliqua and shorter and weaker anterior cingulids. Diacodexis antunesi similarly differs from $D$. pakistanensis by its transverse upper molars with strong 
parastyle and metastyle; it further differs from this Asian species by a larger paraconid on lower molars. Diacodexis antunesi differs from D. parvus in having a metacone and paracone of similar size, an incomplete lingual cingulum, a more posterior orientation of the postprotocrista on M2, and an undivided ectal facet on the astragalus. Diacodexis antunesi differs from Diacodexis sp. from Andarak 2 by more tranverse upper molars with anterior cingulum and sharp endoparacristule.

\subsection{New material from the locality of Fordones, Aude, France.}

Some specimens of Diacodexis from Fordones were described by Marandat (1991) and referred to Diacodexis cf. gazini. This material includes dp4, m1-2, and P2-3, but only the dp4 and the $\mathrm{m} 1$ were figured (Marandat, 1991: pl.4, figs. 10, 12, 14). We provide here additional views of these specimens and figure the loci that were not illustrated in Marandat (1991). Revision of the material referred to Diacodexis by Marandat (1991) revealed that the fragmentary m3 FDN 253 is not Diacodexis and rather belongs to a primate. Additional material from Fordones was collected in 2009. During screen washing, a P3-M3 series was retrieved in the same sieve and most probably belongs to the same individual, the bone of the maxilla was possibly not preserved during diagenesis and only teeth fossilized. Unfortunately, the M1 is missing.

\section{Diacodexis aff. antunesi}

Fig. 8

Synonymy: 1991. Diacodexis cf. gazini-Marandat, pl. 4, figs. 10, 12, 14.

Material (coll. UM): FDN 279, p2 or p3 (right); FDN 122, dp4 (left fragment); FDN 123, dp4 (left); FDN 124, m1 (left); FDN 255, m1 (right); FDN 125, m2 (right); FDN 252, P2 (right); FDN 251, P3 (right); FDN 254, M (fragment); FDN 280, M (left fragment); P3-4 and 
M2-3 FDN 283 (right).

410 Locality and horizon: Fordones, Aude, France; «Grès à nummulitidés» Formation, early

Eocene, $\sim$ MP7.

Measurements: Table 3.

\section{Description:}

Lower dentition. One permanent lower premolar of Diacodexis is documented (FDN

415 279) from Fordones (Fig. 8(D-F)). By its size and morphology, it either represents p2 or p3. Despite wear, a small paraconid is visible. The hypoconulid is central and distinct from the postparacristid. The dp4 (FDN 123) presents a protruding and deeply basined anterior lobe with a high paraconid. The paraconid lies in a central position and slightly extends lingually. The anterior basin is delimited by high and sharp cristids originating from the paraconid and joining the preprotocristid labially and the premetacristid lingually. The cristid joining the protoconid is worn and the lack of a primonid cannot be directly verified; however, there is no swelling of the cristid. The protoconid and metaconid are of equal size, and located on the same transversal plane; both bear postcristids. A small basin is present between the protoconid and metaconid, delimited by incipient endofossids. There is no clear endoprotoand endometa- cristids. The lingual cutting edge of dp4 is composed of high premetacristid, postectometacristid and ectoentocristid. The entoconid also bears a small endoentocristid and a sharp postentocristid. The latter is not connected to the posthypocristid. The cristid obliqua connects the base of the metaconid. There is no hypoconulid. Concerning the root pattern, the dp4 bears only two pillars, there is no trace of third labial pillar (see discussion). A fragmentary dp4 documenting the trigonid (FDN 122) shows the same morphology as FDN 123.

The lower molars are documented by two $\mathrm{m} 1$ and one $\mathrm{m} 2$. All specimens are worn and the finest structures of the crest and groove pattern have been worn away. The specimens 
show a long and thin anterior cingulid; the labial cingulid is absent. Compared to $\mathrm{m} 1$, the trigonid of $\mathrm{m} 2$ is more compressed due to the posterior position of the paraconid (appressed to the metaconid). On m1-2, the cristid obliqua joins the base of the protoconid (Fig. 8(G-L)). Marandat (1991) considered that the hypoconulid was absent and that the entoconid was connected to the posterior cingulid. However, these observations are related to the wear of the teeth, a small groove and the shape of the exposed dentine indicate that a small hypoconulid was indeed present. The apparent connection of the entoconid to the posterior cingulum is also due to wear. The talonid notch is deep and marked.

Upper dentition. The upper dentition of $D$. aff. antunesi is documented by two isolated premolars and by an upper tooth raw comprising P3-4, M2-3 (FDN 283). The P2 (FDN 252) is slightly inflated in its posterolingual part, but its posterior-most portion is broken (Fig. 8(Q)). There are sharp and high pre- and post- paracristae. A very small parastyle lies anteriorly to the preparacrista. The postparacrista and preparacrista are finely crenulated. The P3 is documented by two specimens (FDN 283, FDN 251). It has a triangular outline (Fig. $8(\mathrm{P}))$ and three well separated roots, one anterior, one posterior and one supporting the lingual lobe. The paracone bears sharp and high pre- and post- paracristae. The parastyle is salient and distinct from the preparacrista. The postparacrista joins the posterior cingulum at the level of the metastyle. The lingual lobe is small and bears no protocone; a small basin is present, lined by a thin lingual cingulum. In both specimens, the lingual cingulum is continuous with the posterior one. The $\mathrm{P} 4$ shows a rather small protocone, which summit is more anterior than that of the paracone $($ Fig. $8(\mathrm{O}))$. The protocone bears a sharp preprotocrista joining the anterior cingulum, but no posterior crista. There is no endoprotocrista and no endoparacrista. The posterior cingulum is thick, long and joins a small metastyle on the posterolabial corner of the tooth. The cingulum is interrupted lingually at the protocone level. The labial cingulum is thin and continuous. There is no ectoflexus. 

and the lingual lobe is antero-posteriorly wide. The anterior cingulum is long and ends lingually at the level of a small pericone whereas the posterior cingulum is less extensive but

462

thicker with a small hypocone. The parastyle is small. Wear does not obscure the presence of the endoproto- and endometa-cristules. The M3 is triangular in shape. It exhibits a pronounced ectoflexus and the paracone is larger than the metacone (Fig. 8(M)). The protocone is smaller than on M2. The anterior cingulum joins lingually a small pericone. In the upper tooth raw, the size of M3 is only slightly smaller than M2, whereas P4 is considerably smaller than the latter (Fig. 8(M-O)).

Enamel microstructure. The 'basic' radial enamel of the upper molar FDN 254 from Fordones has the same characteristics as that of D. antunesi (Fig. 3). It is slightly thinner (84 $\mu \mathrm{m})$ and the IPM cristallites are directed to $33^{\circ}$ relative to the prism direction. Prisms rise from the EDJ at an angle of $65^{\circ}$ and reach EOS with an angle of $72^{\circ}$. The aprismatic outer enamel layer is thicker than in D. antunesi: it represents on average $20 \%$ of total enamel thickness.

Remarks: $D$. aff. antunesi is morphologically very close to $D$. antunesi from the slightly older locality of Silveirinha, Portugal. The upper teeth are generally the same size: upper molars fall in the range of variation observed in D. antunesi, the P4 is slightly larger labiolingually (Fig. 5). However, greater size difference is observed for m1-2, with specimens of $D$. aff. antunesi from Fordones larger than those of D. antunesi (Fig. 4). Compared to D. antunesi, m1-2 of $D$. aff. antunesi have a larger entoconid that widens the talonid part of the tooth. Both taxa show the same crest pattern and a hypoconulid closely linked to the entoconid, as well as subequal trigonid and talonid, separated by deep labial and lingual notches (Fig. 7(C)). Like D. antunesi, the P4 of D. aff. antunesi has no ectoflexus; however, the parastyle and the paracone are smaller and the endoparacristule is lacking in $D$. aff. 
antunesi. The P3 of $D$. aff. antunesi differs from that of $D$. antunesi by a slenderer distal part with a weaker cingulum. Because of these differences and of the small number of remains available from Fordones, we decided to refer it to as $D$. aff. antunesi.

Marandat (1991) referred the Diacodexis remains from Fordones to Diacodexis cf. gazini based on dimensions of the lower molars slightly larger than D. antunesi and on characters he considered also present in D. gazini: lack of hypoconulid on lower molars, entoconid small and fused to the posterior cingulid, a paraconid close to the metaconid. Based on our new observations, the absence of hypoconulid in the lower molars of Fordones and in the specimens of D. gazini from Rians is due to wear: the hypoconulid has been worn away; the connection of the entoconid to the posterior cingulid and the proximity of the paraconid and metaconid are also characters related to the wear stage of the teeth. Compared to $D$. gazini from the more recent locality of Rians (Marandat et al., 2012), D. aff antunesi from Fordones has less internal paraconid and metaconid and thinner cingulids on lower molars. Upper molars of $D$. aff antunesi have more pointed cusps, the lingual lobe of M2 is proportionally wider in D. gazini due to massive cingula. The ectoflexus of upper molars is shallower in D. gazini (Fig. 7(C) vs (E)). Like D. antunesi, D. aff. antunesi is morphologically very close to $D$. varleti but shows smaller dimensions of upper and lower teeth. The M2 specimen from Fordones is much smaller, but M3s of both species have the same labiolingual diameter but they are much longer in D. varleti (Fig. 5). The dp4 of D. varleti (CB 811) is also mentioned in the literature (Sudre 1983:295) but could not be found in the MNHN collections and is possibly lost. D. aff. antunesi from Fordones differs from other early Ypresian Diacodexis species for the same characters as those mentioned for D. antunesi. For additional comments on enamel microstructure and dp4 morphology and comparisons with other Diacodexis species, see discussion section. 

Palette, identified and prepared in 2012, confirms the presence of this genus in this locality.

\section{Diacodexis cf. gigasei}

Figs. 9-10

Referred material (coll. UM): PAT 159, dentary with p3-m3 and alveoli i1-p2 (left); PAT 136, m1 (left); PAT 19, astragalus (left); PAT 168, astragalus (right).

Locality and horizon: Palette, Bouches-du-Rhône, France; at the top of the «Calcaires de Langesse», early Eocene, $\sim \mathrm{MP7}$.

Measurements: Tables 2, 4.

\section{Description:}

Dentary. PAT 159 consists in a left dentary preserving p3-m3 (Fig. 9). The anteriormost part of the mandible is preserved and the alveoli of i1-p2 are visible. The body of the mandible is free from deformation and complete except for a small portion of its ventral edge, broken under $\mathrm{p} 4-\mathrm{m} 1$. The posterior part of the mandible, including the angular apophysis, is missing. The ascending ramus is deformed: its height and width are diminished by fractures and medial sliding of the bone. The 3D model of the originally preserved state specimen as well as a 3D model showing a reconstruction of the ascending ramus based on the preserved fragments are available at MorphoMuseuM.com (Orliac et al., in press; models ID: M3\#315_ UMPAT159, M3\#317_UMPAT159). PAT 159 constitutes the most complete specimen of European Diacodexis to date, and the longest tooth row documented for the same individual for European Diacodexis species. The body of the mandible is particularly slender and low, especially in the incisors and canine region, and slightly increases from the incisors to the 
molars, but is of constant height between $\mathrm{p} 3$ and $\mathrm{m} 2$. The body of the mandible is particularly shallow at the level of $\mathrm{p} 1$ where it slopes downward (Fig. 9(A-B)). Three mental foramina are present on the labial surface: one below the p1, one below the posterior root of the $\mathrm{p} 2$, and one between the $\mathrm{p} 3$ and $\mathrm{p} 4$. The first mental foramen is the largest. The mandibular symphysis starts from the level of $\mathrm{p} 2$. Despite of breakage of the posterior part of the mandible, the coronoid apophysis is complete; it is slightly curved posteriorly and shows a wide plateau at its dorsal extremity. Its dorsal extension is weak: its height is similar to the height of the body of the mandible at the level of $\mathrm{m} 3$. This is, to our knowledge, the first documentation of a complete coronoid apophysis for Diacodexis, except the conceptual reconstruction provided by Russell et al. (1983: fig. 1) for D. pakistanensis in which the dorsal extremity was figured in dotted lines. The anterior part of the mandibular condyle is preserved, separated from the ascending ramus by a wide incisura. The condyle, which was small in size, was situated well above the tooth row. There is a large space between the root of the ascending ramus and the posterior part of $\mathrm{m} 3$. Based on the disposition of the alveoli on the anterior portion of the mandible, there were three short diastemata between $\mathrm{p} 3$ and $\mathrm{p} 2$, between $\mathrm{p} 2$ and $\mathrm{p} 1$, and between $\mathrm{p} 1$ and canine. The canine and the $\mathrm{p} 1$ are single-rooted, the $\mathrm{p} 2$ is double-rooted and its size was probably similar to that of the $\mathrm{p} 3$. The alveolus of $\mathrm{p} 1$ and that of the canine are similar in size. Judging from the size of their alveoli, the incisors of $D$. cf. gigasei were minute. Alveoli of i1-i2 are coalescent.

Lower tooth row. The $\mathrm{p} 3$ has a tiny paraconid connected to the protoconid via the preprotocristid. The postprotocristid joins the posterolingual cingulid but the hypoconid only consists in a bulge of the posterior cingulid. The $\mathrm{p} 3$ has no anterolabial cingulid. The $\mathrm{p} 4$ is wider than $\mathrm{p} 3$, longer, and has a more distinct paraconid and a rather larger hypoconid than p3. Compared to p3, a small anterolingual cingulid is present and the anterior and posterior basins are more elongate. Three posterior crests originate from the protoconid, a long 
postprotocristid, and short endoprotocristid and postectoprotocristid. On p3-4, the preprotocristid is labial and is shifted lingually in its anteriormost portion to join the paraconid. The $\mathrm{m} 1$ is antero-posteriorly shorter than $\mathrm{p} 3$ and $\mathrm{p} 4$. The $\mathrm{m} 2$ is the widest molar labio-lingually and its length is clearly superior to that of $\mathrm{m} 1$ (Table 4). On m1-3, the talonid is larger than the trigonid; the cristids of the trigonid are close together and the trigonid basin is narrow. The paraconid is almost as high as the protoconid, which itself is small and close in size to the metaconid. The protoconid and the metaconid are about the same height. The paraconid is distinct from the metaconid on $\mathrm{m} 1$, these two cuspids being less separated on m2-3. In spite of wear, the endoprotofossid and endometafossid are present. The talonid notch is weak and the postectometacristid is absent on m1-3. The entoconid is located lingually and large but smaller than the hypoconid. The cristid obliqua is directed toward the metaconid on $\mathrm{m} 1$ and central on $\mathrm{m} 2-3$. The anterior cingulid is long and almost continuous with the labial cingulid on m2-3. The hypoconulid is linked to the entoconid, to the hypoconid and to the posterior cingulid except on $\mathrm{m} 3$ where it is separated from the labial cingulid by a groove. The posterior lobe of the $\mathrm{m} 3$ is massive and bears a large hypoconulid.

Astragalus. Two astragali retrieved in Palette are referred here to the species $D$. cf. gigasei. They are identical in terms of size and proportions. The proximolateral part of the tibial trochlea is missing on the astragalus PAT 168 whereas the astragalus PAT 19 is almost complete, with only the tibial trochlea lateral condyle and the distal calcaneal facet partly broken (Fig. 10(A-D)). The two trochlea of the astragalus PAT 19 have the same width. In both specimens, the groove of the tibial trochlea is wide and shallow, and the condyles are nearly symmetrical proximally. The fossa for the anterior process of the tibia is present on PAT 19 (corresponding part broken on PAT 168). On both specimens, the distal trochlea is robust and has a very prominent cuboid facet, which is especially pronounced on PAT 19. The fossa for the tibial malleolus is deep and the sustentacular facet is long and strongly 
convex in lateral view. The surface where fits the calcaneo-navicular ligament is wide on both specimens. The ectal facet is shrunk in its center, and its upper part is round. The ectal facet is separated from the sustentacular facet by a narrow sulcus tali. Slight differences are observed between the two specimens: the neck of PAT 19 is narrower than that of PAT 168 (Fig. 10(A) vs (E)) and its lateral cavity is deeper.

\section{Remarks:}

\section{Comparison with other known Diacodexis dentaries. Dentaries of Diacodexis figured}

in the literature are scarce and, to our knowledge, only available for D. indicus (Kumar et al., 2010: fig. 5E), D. secans (Krishtalka and Stucky, 1985), and D. pakistanensis (Russell et al., 1983: fig. 1; Thewissen et al., 1983). A decent fragment of the mandible of $D$. ilicis is also illustrated in Gingerich (1989). The morphology of the mandible remains undescribed for European taxa so far. The three diastemata observed in D. cf. gigasei (between $\mathrm{p} 3$ and $\mathrm{p} 2$, between $\mathrm{p} 2$ and $\mathrm{p} 1$, and between $\mathrm{p} 1$ and canine) are also present in D. pakistanensis as figured by Russell et al. (1983: fig. 1). The material illustrated by Thewissen et al. (1983: pl. 2) shows that variability occurs in that species and that the $\mathrm{p} 3-\mathrm{p} 2$ diastema can be present or absent (Thewissen et al., 1983: pl. 2.4 vs 5). Short diastemata between $\mathrm{p} 2$ and $\mathrm{p} 1$ and $\mathrm{p} 1$ and canine are also present in D. indicus (Kumar et al., 2010: fig. 5E) and D. secans (Krishtalka and Stucky, 1985). The p3-p2 diastema is also observed in D. secans (Krishtalka and Stucky, 1985), but does not seem to be present on the specimen of D. indicus (Kumar et al., 2010: fig. 5E). Compared to the specimen of D. pakistanensis figured by Thewissen et al. (1983: pl. 2.4a), to D. indicus (Kumar et al., 2010: fig. 5G) and to D. ilicis (although most probably deformed, Gingerich, 1989: fig. 36B) the body of the mandible PAT 159 only slightly increases in height posteriorly between $\mathrm{p} 3$ and $\mathrm{m} 3$. The downward curve of the anterior part of the mandible, anterior to $\mathrm{p} 2$ at the level of $\mathrm{p} 1$ (that is of the symphysis) observed on PAT 159 is neither present on the specimen of D. pakistanensis illustrated by Thewissen et al. 
(1983: pl. 2.4a) nor on that of D. indicus illustrated by Kumar et al. (2010: fig. 5G). This downward slope of the anterior-most region of the mandible is however perceptible on the occluding tooth row of D. pakistanensis (Thewissen et al., 1983: pl. 1.3a) and is observed in other artiodactyls of the Eocene (e.g. Chorlakkia Gingerich et al., 1979). The main mental foramina observed on the labial surface of PAT 159 are also present in the other Diacodexis species. The space between the root of the ascending ramus and the posterior edge of $\mathrm{m} 3$ is superior in PAT 159 than in other Diacodexis species for which this character is documented (D. pakistanensis, Russell et al., 1983; D. ilicis, Kumar et al., 2010).

Comparison of the tooth row with other early-middle Ypresian Diacodexis species. The dentition of $D$. cf. gigasei can only be partially compared to other European Diacodexis species because its upper dentition is not documented, and because lower premolars of most of the other Diacodexis species are not documented: the p3 can only be compared to $D$. antunesi, D. gazini and D. aff. antunesi, the 44 can only be compared to D. morrisi. In terms of size, the dental remains of $D$. cf. gigasei from Palette are generally larger than those of $D$. antunesi, and close in size to other MP7 species from Southern Europe (Fig. 4). Comparison with Southern European MP7 and MP8+9 species. The lower dentition of $D$. cf. gigasei shows clear differences with that of $D$. antunesi. The p3 has a longer preprotocristid, more curved lingually than the $\mathrm{p} 2 / 3$ ? of $D$. antunesi, which is also labiolingually slenderer. These differences can be due to the fact that SNC 64 is in fact a p2 rather than a p3. Concerning the lower molars, compared to D. antunesi, D. cf. gigasei presents a proportionally smaller trigonid that represents less than half of the crown surface. The trigonid basin is slender, and shallower and the paraconid is very close to the metaconid. The postectometacristid is absent in D. cf. gigasei whereas it is long sharp and connected to the ectoentocristid in D. antunesi. The cingulids of D. cf. gigasei are longer and the anterior cingulid is almost connected posteriorly to the labial one. The hypoconulid is located closer to 
the median plane of the tooth in D. cf. gigasei. In this latter taxon, there is a marked difference of height between the protoconid and the lingual cuspids, whereas in $D$. antunesi this difference is weaker. The astragalus of $D$. cf. gigasei from Palette is more robust than that of D. antunesi (Fig. 2 vs Fig. 10, Table 2). The narrowing at the level of its neck is less pronounced and the tibial trochlea groove is wider and the sulcus tali narrower than in $D$. antunesi. Compared to D. aff. antunesi from Fordones, the $\mathrm{p} 3$ of $D$. cf. gigasei presents much smaller paraconid and hypoconulid, and a longer preprotocristid, more curved lingually. The lower m1-2 of D. cf. gigasei are wider with longer cingulids and a more medial position of the hypoconulid. Compared to D. gazini, the $\mathrm{p} 3$ of $D$. cf. gigase $i$ shows a wider protoconid than that of the $\mathrm{p} 2 / 3$ ? of the former species, a more central/medial position of the paraconid which is fused to the anterior cingulid. The tooth is labio-lingually slenderer in D. gazini. These differences might be due to the fact that RI 208 is in fact a 22 rather than a 33 . The $\mathrm{m} 2$ of $D$. cf. gigasei differs from that of $D$. gazini by a wider and lower crown; $D$. gazini shows a proportionally slenderer and smaller trigonid relative to the talonid and a longer anterior cingulid. Like in D. gazini, D. cf. gigasei has a paraconid very close to the metaconid. Compared to D. cf. gigasei, D. varleti presents a hypoconulid of m1-2 situated closer to the entoconid, a protoconid almost as high as the metaconid on lower molars, a shorter anterior cingulid, sharper lingual crests (postectometacristid absent in D. cf. gigasei). The groove separating the metaconid and the paraconid is deeper in D. varleti than in D. cf. gigasei. Finally, D. cf. gigasei differs from $D$. corsaensis by a smaller size of the $\mathrm{p} 4$ and larger size of m3 (Fig. 4).

Comparison with Northern European MP7 species. The Diacodexis material from Palette is close to D. gigasei from Dormaal (Belgium) in its size, and morphologically speaking by the presence of: i) a long anterior cingulid on $\mathrm{m} 2$, ii) a reduced lingual cutting edge on lower molars (low ectoendocristid and no clear postectometacristid), iii) an 
659

660

661

662

663

664

665

666

667

668

669

670

671

672

673

674

675

676

677

678

679

680

681

682

683

hypoconulid apart from entoconid on $\mathrm{m} 1-2$, iv) a postentocristid directed toward the hypoconulid on m3. Lower molars from the two localities differ by their length/width ratios which are smaller for m1-2 of D. cf. gigasei than in those from Dormaal (Fig. 4). In D. cf. gigasei, the m3 paraconid also appeared reduced and the molar crown looks slightly more bunodont, but this can be due to difference in wear stages. As a result, despite the good morphological and close metrical correspondence between the material from Palette and that collected from Dormaal, the Diacodexis material from the former locality is left under open nomenclature as D. cf. gigasei. Further discoveries, especially that its upper molars, could clarify this attribution.

The p4 of D. cf. gigasei differs from that of D. morrisi (Hooker, 2010: fig. 47d,g) by a longer preprotocristid, more curved lingually, and by a shorter postectoprotocristid. Both taxa present three posterior crests originating from the protoconid, endoprotocristid, postprotocristid and postectoprotocristid. The $\mathrm{m} 1$ of $D$. morrisi shows a more open trigonid basin with a larger paraconid located more lingually than in D. cf. gigasei. The labial notch, in occlusal view, is deeper on $\mathrm{m} 1$ and $\mathrm{m} 3$ in $D$. morrisi and a long and sharp postectometacristid is present.

Comparison with Northern American and Asian species. D. cf. gigasei is smaller than D. indicus and all Northern American species; moreover, it has no postectometacristid in contrast to all North American and Asian species; it differs from D. parvus and D. indicus by a more central location of the hypoconulid. Finally, D. indicus and D. pakistanensis have a more labial cristid obliqua. The $\mathrm{p} 4$ of $D$. cf. gigasei differs from that of D. ilicis and D. secans primus in lacking a distinct lingual demarcation/inflexion of the paraconid. In D. ilicis, the lingual basin on the talonid is deeper and bordered by a thick posterior cingulid. The presence of the three posterior crests on $\mathrm{p} 4$ cannot be ascertained based on the low resolution figures provided by Rose et al. (2012) and Krishtalka and Stucky, (1985). There seem to be a stronger 
684

685

686

687

688

689

690

691

692

693

694

695

696

697

698

699

700

701

702

703

704

705

706

707

708

endoprotocristid and no postectoprotocristid on the North American specimens.

3.4. New material from the locality of La Borie, Aude, France.

Diacodexis sp.

Fig. 11

Referred material (coll. UM): BRI 1, P3 (right); BRI 2, P4 (left); BRI 3, M2 (right); BRI 4, M3 (right); MHNT.PAL.2017.21.2, m2 on a fragmentary dentary (left).

Locality and horizon: La Borie, Aude, France; «Argiles rutilantes d'Issel et de Saint-Papoul» Formation, early Eocene, $\sim \mathrm{MP} 8+9$.

Description: The unique lower molar is much worn; considering the size of its trigonid and the morphology of the preserved roots of the anterior teeth, MHNT.PAL.2017.21.2 is attributed to an $\mathrm{m} 2$. No peculiar detail of the crown is visible.

The upper dentition is documented by premolars and molars. The P3 (BRI 1) has a triangular outline (Fig. 11(D)) and three distinct roots (anterior, posterior, lingual). The paracone bears sharp and high pre- and post- paracristae, crenulation cannot be observed because of wear. There is no trace of parastyle, but the corresponding locus is slightly worn; if present, it was very small. There is no metastyle. The lingual lobe is large and protrudes lingually; it bears a small protocone and a small basin. The lingual cingulum is continuous and joins the anterior and posterior cingula. The labial cingulum is very thin. The P4 (BRI 2) has no ectoflexus (Fig. 11(C)). This tooth is remarkably unworn. The unworn paracone is very high. Parastyle and metastyle are present, the metastyle being higher than the parastyle. The P4 has a small protocone which summit is slightly anterior to that of the paracone. It bears anterior and posterior cristae. There are no endoproto- and endopara- cristae, nor anterior and posterior cingula.

The M2 (BRI 3) is only little worn but is broken anterolingually (Fig. 11(B)). It has 
round labial corners. The labial edge is straight. The paracone is higher and slightly larger than the metacone. The preparacrista and postmetacrista are both on the same plane as the centrocrista. The endoparacristule and endometacristule are present, but the endoparacristule is very low. There is not a postmetacristule deflection (i.e. postmetacristule protruding on the posterior edge of the tooth, cf. Fig. 7B, F) on the occlusal surface. The styles are limited to cingular swellings. The posterior cingulum is short, there is no clear hypocone. The M3 (BRI 4) is little worn. It has round labial corners and a tilted lingual edge (Fig. 11(A)). The paracone is the highest cusp. The preparacrista and postmetacrista are both on the same plan as the centrocrista. The anterior and posterior cingula are long, thick, but not connected at the protocone level.

\section{Remarks:}

Comparison with Southern European MP7 and MP8+9 species. The taxon from La Borie is larger than $D$. antunesi and smaller than $D$. morrisi. It differs from $D$. antunesi and $D$. gigasei in having no postmetacristule deflection on the occlusal surface. It differs from $D$. antunesi in having a P3 with an elongate paracone and more convex labial edge, a reduced parastyle on upper molars. It differs from other species of Diacodexis in having a P4 without anterior and posterior cingula. It differs from D. gigasei in having a P4 without ectoflexus and upper molars with shorter posterior cingulum (no lingual bulge). It differs from $D$. morrisi in having no endoparacrista and a less important groove intersecting the postprotocrista on upper molars.

The material of La Borie appears close to D. gazini in size and morphology. Both species have round labial corners on upper molars, straight labial edge on M2, and similar mesiodistal M2 length. On M3 however, the Diacodexis species from La Borie has a less protruding parastyle and strongly round cusps and conules when compared to D. gazini. Conversely, the M2 of La Borie does not show bulbous cusps like for the M3 of D. gazini. 
This discrepancy could be explained by the degree of wear (the M2 is almost unworn contrary to the M3). Finally, the M2 from La Borie does not have a long and thick posterocingulum shaping in hypocone while the presence of the latter feature constitutes a diagnosic character of D. gazini. Finally, compared to D. varleti, the species from La Borie has less pronounced ectoflexus on M2, the parastyle is not protruding, and the conules are reduced with lesser endocristules.

Comparison with Northern American and Asian species. The taxon from La Borie is smaller than D. indicus and all North American species; it further differs from D. ilicis in having no postmetacristule deflection. Among Asian species, Diacodexis sp. from Andarak 2 and D. pakistanensis differ from Diacodexis sp. from La Borie by the lack of endoparacristule and postprotocrista on upper molars and P4, respectively; Diacodexis indicus has a larger parastyle on M2 and a more reduced metacone on M3.

\section{Discussion}

\subsection{Ancestral morphotype of artiodactyl enamel microstructure}

Recent data on artiodactyl enamel microstructures revealed a diversity of patterns relevant to phylogenetic inferences (Alloing-Séguier et al., 2014). From this point of view, Diacodexis is crucial to discuss the enamel ancestral morphotype of artiodactyls. Since Maas and Thewissen (1995) and Stefen (1999), Diacodexis is thought to have developed a twolayered Schmelzmuster (the spatial arrangement of the different enamel types through enamel thickness): a thin layer (5-10\%) of radial enamel close to EDJ and a thick layer of HunterSchreger bands (HSB) that generally extends to the EOS; in some parts a very thin layer of radial enamel can occur at the EOS. Our data on Diacodexis antunesi and Diacodexis aff. antunesi, which have a one-layered Schmelzmuster with 'basic' radial enamel only, reveal a 
simple enamel pattern. This result implies a surprising interspecific variability among Diacodexis species, which is rare among eutherian mammals.

Maas and Thewissen (1995) based their observations on Diacodexis on an undetermined North American species represented by a lower molar from the Wa-5 (= 'Bunophorus Interval Zone' in the original publication). Regarding Stefen (1999)'s analysis, two species were studied based on specimens from the UCMP collections, i.e. Diacodexis robustus and an undetermined species. Theodor et al. (2007) now attribute the former species to Bunophorus; this diacodexeid genus is thus excluded from the present discussion. As for the undetermined Diacodexis, online UCMP database (accessed on September 2017, available at: http://ucmpdb.berkeley.edu/) indicates that the figured specimen comes from the midWasatchian (Wa3-5) (= 'Graybullian' in the database) of the Willwood Formation, Wyoming. Therefore, based on the stratigraphical ranges proposed by Krishtalka and Stucky (1985) for North American Diacodexis species, we can assume that the undetermined species studied by Maas and Thewissen (1995) and Stefen (1999) is either D. secans (known from the early Wasatchian to the Bridgerian) or less probably D. gracilis (rare, known in the midWasatchian, Wa3-5). Importantly, Diacodexis antunesi and Diacodexis aff. antunesi are smaller and have more crestiform, simple molars than D. secans and D. gracilis. These size and morphological differences could be correlated to the dissimilar enamel microstructure that we observe between Diacodexis species.

Actually, according to Koenigswald et al. (1987), HSB characterized almost all large herbivorous mammals since the early Paleocene. Stefen (1999) proposed that convergent evolution of HSB within eutherians result of co-occurring changes in dental morphology, body-size, overall ecology, and chewing pattern. Fundamentally, small insectivorous mammals have 'basic' radial enamel (e.g., eulipotyphlans, chiropterans, small primates, some “condylarths") whereas herbivorous, omnivorous, and mid-sized carnivorous and large 
mammals have prism decussation such as HSB. Interestingly, our results on Diacodexis, would support this trend at the genus level: $D$. antunesi and $D$. aff. antunesi are small-sized most likely insectivorous species with tribosphenic, crestiform molars, whereas D. secans and D. gracilis are putative omnivorous and/or herbivorous, larger species with more quadritubercular, bunodont molars (see also Theodor et al. 2007: p. 37). Interestingly also, the fossil record of placental mammals suggests that the 'basic' radial enamel is the primitive condition (see Tabuce et al. 2017: p. 103). With the exception of odontocetes (due to the simplification of their tooth morphology and piscivorous diet), there are no reversion from HSB to 'basic' radial enamel. In other words, the enamel microstructure (i.e., 'basic' radial enamel) of Diacodexis antunesi most likely represents the primitive condition among Diacodexis species and most probably represents the ancestral morphotype for Artiodactyla.

\subsection{Ancestral morphotype of artiodactyl fourth lower deciduous premolar}

The new Diacodexis material described here includes one dp4 attributed to $D$. aff antunesi (Figs. 8A-C, 12A). This specimen from the Ypresian locality of Fordones represents one of the earliest record of dp4 for artiodactyls. Only few specimens of dp4 of Diacodexis are documented in the literature. A dp4 of D. varleti was reported by Sudre et al. (1983) from Condé-en-Brie, but the specimen was neither figured nor described by the authors, and could not be found in the MNHN collections. In addition to this specimen, a dp4 of D. morrisi has been described and figured by Hooker (2010: fig. 48E). This specimen is fresh and allows observing the finest structures of the crown (Fig. 12(B)). In addition to these specimens, several dp4s of early artiodactyls are documented from the French MP10 locality of Prémontré (Aisne, Nothern France). One specimen, SLP-29-PE 637 (Fig. 12(E)), was originally attributed to D. cf. varleti by Sudre and Erfürt (1996) but it was not figured. Four 
other dp4 of artiodactyls from the same locality were referred to Dichobunidae Eurodexeinae by Sudre and Erfürt (1996: pl. 1, fig. 8; Fig. 12(F)). Since the publication of this material, another specimen was retrieved from the sediment from Prémontré. This specimen, UM PRE151, is here attributed to Diacodexis sp. (Fig. 12(D)). From Asia, a worn dp4 of D. indicus was described by Kumar et al. (2010: fig. 6G-I; Fig. 12(C)) from the Vastan mine in Western India. Luckett and Hong (1998) paid special attention to the morphology of the lower fourth deciduous premolar in extant and fossil artiodactyls. In artiodactyls, the anterior lobe of the trilobed dp4 is described as bearing a mesiolabial and a mesiolingual cusp, forming a third lobe, a character retrieved as a synapomorphy of Artiodactyla (e.g., Gentry and Hooker, 1988; Luckett and Hong, 1998). Luckett and Hong (1998) consider that the paraconid is anteriorly displaced and lingual, and that "the anterior lobe of the artiodactyl $d P_{4}$ is characterized by the development of a neomorphic cusp on the paracristid that runs between the protoconid and the paraconid; this new cusp provides a "squaring" of the anterior portion of the tooth" (Luckett and Hong, 1998: p. 135). Surprisingly, these authors illustrate a specimen they refer to as Diacodexis cf. varleti from the French locality of Prémontré and numbered SLP 29PR 2122, while this specimen was initially attributed to Eurodexeinae indet. by Sudre and Erfürt (1996). A line drawing of the occlusal surface of the crown of SLP 29PR 2122 (Fig. 12(F)) shows that its general pattern considerably differs from that of dp4 of other Diacodexis species and that this specimen might indeed belong to the Eurodexinae. In turn, as illustrated on Figure 12, the MP7 European specimens referred to Diacodexis all present only one large cupid on what is generally considered as the anterior lobe or "paraconid lobe" (Hooker, 2010). This cusp is located on the lingual border of the tooth, and bears its own crest pattern with a lingual and a labial crest, touching the premetacristid and the preprotocristid respectively. According to its lingual position, this anterior cusp might be called the paraconid. The anterior part of the tooth rather has a triangular shape and there is no 
"squaring" of the anterior portion of the tooth, as described by Hooker (2010: p. 108) based on the specimen of $D$. morrisi. The general shape of the crown is hourglass rather than trilobed, and there is no constriction between the paraconid lobe and the rest of the trigonid. In the specimens of Eurodexis russelli from Prémontré (Sudre and Erfürt, 1996: pl. 1, fig. 8), an additional cuspid is present labial to the large paraconid and the anterior part of the tooth is indeed squared; it presents a trilobed outline, like in most other extant and extinct artiodactyls. On the very fresh dp4 of Diacodexis sp. from Prémontré (UM PRE151, Fig. 12(D)), a very small accessory cuspid is present on the labial crest originating from the paraconid. The dp4 from the same locality attributed to Diacodexis cf. varleti, by Sudre and Erfürt (1996) in fact presents a completely different morphology: there is one main cusp which is displaced labially and connected to the protoconid, a series of accessory cuspids are present in a crestlike structure, not mesiolabially, but lingually (Fig. 12(E)). There is no anterior basin. These two specimens illustrate the potential intraspecific variation for $\mathrm{dp} 4$.

These observations suggest that the labial anterior cuspid appears after the lingual one, here recognized as the paraconid based on its lingual position. Then it seems logical to recognize the anterior lingual cuspid as the paraconid and the labial one as the primonid, as identified by Luckett and Hong (1998). This nomenclature however contrasts with that used by authors for other artiodactyl groups such as suoids (Made, 1996; Orliac and Ducrocq, 2012; Orliac et al., 2015) where the labial cusp is named the paraconid and the lingual one the primonid. Early European Diacodexis dp4s suggest the opposite homology. In the phylogenetic analyses of Theodor and Foss (2005), the dp4 of Diacodexis is considered to be six cusped based on observations of Diacodexis pakistanensis. In contrast, observations of Ypresian material from Europe indicate that early Diacodexis species have only one anterior cuspid on dp4. Besides, the presence of two basins only, and the hourglass outlines of the dp4 of earliest Diacodexis species, do not match the trilobed pattern traditionally considered as a 
synapomorphy for Artiodactyla. Finally, the dp4s of Diacodexis bear two pillars only, which contrasts with the three rooted pattern of most more derived artiodactyls. The presence of a two rooted pattern also occurs in other early members of Artiodactyla (Dichobunidae, Cainotheriidae, Choeropotamidae; Orliac pers. obs.) as well as in basal members of Suoidea (Orliac et al., 2012), and might represent the primitive condition within Artiodactyla.

\subsection{Relationships within Diacodexis and paleobiogeographic inferences}

Artiodactyls appear rather abruptly in earliest Eocene deposits in the fossil record (Gingerich, 2006). Because of their early occurrence and the simple tribosphenic pattern of their molars, Diacodexis has been regarded as a paraphyletic ancestral pool of species near the base of the artiodactyl radiation (Rose, 2006), and was considered as implicated in the origin of some European Eocene endemic groups (Sudre and Erfurt, 1996; Checa Soler, 2004), as well as North American groups (Krishtalka and Stucky, 1985). The position of Diacodexis species varies depending of the sample included in phylogenetic analyses (e.g., Theodor and Foss, 2005; Geisler et al., 2007; Orliac and Ducrocq, 2012).

Diacodexis shows a vast repartition of species, close in terms of morphology and stratigraphic age, despite sometimes huge geographic distances. For several taxa, mostly for European ones, only few specimens are available. On the other hand, species documented by relatively abundant material indicate that intraspecific variation occurs and might affect features used to differentiate species (e.g., morphology of the m3 talonid, of the cingulids). Besides, the absence of complete skull, or even tooth raw preservation, makes association of upper and lower dentition problematic for some taxa (e.g., Diacodexis cf. varleti; Sudre et al., 1983: p. 302). In addition to these taphonomic/preservation bias, wear degree has a potentially drastic impact on crown morphology and the way it can be described by authors. Several features, such as relative height or size of cusp(id)s, or accessory crest pattern can be affected 
883

884

885

886

887

888

889

890

891

892

893

894

895

896

897

898

899

900

901

902

903

904

905

906

907

by wear. To be reliable, comparisons should be performed between specimens showing the same degree of wear, which is not always possible given the scarcity of available material for some taxa.

The new material described here shows that premolars, deciduous dentition, as well as enamel microstructure are informative for systematic and phylogenetic purposes. However, these characters are incompletely represented in several Diacodexis species, limiting the extent of comparisons. Their rather simple molar morphology, combined to potential intraspecific variation, dental locus association problems, impact of wear on morphology, continuity of most of the characters described (cusp/id bulging, relative size, height, conule location, cingulum/id size, length), and to the incompleteness of the loci documented between localities/taxa, are factors that hinder the implementation of a phylogenetic analysis of Diacodexis species so far.

Yet, relationships of European Diacodexis species have been discussed in the literature based on comparisons between taxa only and not on formal cladistic analyses. D. antunesi has been regarded as the most primitive Diacodexis species by some authors (e.g. Smith et al. 1996; Theodor et al., 2007); Hooker (2010) instead considers that D. gigasei from Dormaal (MP 7) represents the most primitive species of the genus. Based on outgroup comparison polarization criterion with hyopsodontid and arctocyonid 'condylarths', Hooker (2010) considers that some characters point to $D$. antunesi being relatively derived within Diacodexis species. These characters are: on lower molars, the crown height, the lingual position of the m1-2 hypoconulid, the constriction of the $\mathrm{m} 3$ hypoconulid lobe, and the bulging of $\mathrm{m} 1-2$ entoconid; and on upper molars, the occlusal pattern of distolabially directed M1-2 postprotocrista, and a "bowed centrocrista". The lower molars of D. antunesi indeed present a hypoconulid closer to the entoconid and located more lingually than what is observed in $D$. gigasei. For this character D. antunesi is closer to D. varleti from Condé-en-Brie, France, but 
also to D. indicus from Vastan, India (Fig. 13). However, based on our observations, the entoconid of $D$. antunesi does not appear to be particularly larger than that of D. gigase $i$ on m1 (Fig. 13(B) vs (F)). Smith et al. (1996) propose that D. gigasei and D. antunesi share a continuous structure uniting the hypoconulid and the hypoconid, a character seen by these authors as plesiomorphic. This continuous structure might result from wear pattern on the specimens, yet, study of fresh teeth indicates that the hypoconulid and the hypoconid are always separated by a groove (Fig. 13). For upper molars, the "bowing of the centrocrista" mentioned by Hooker (2010), is, to us, directly related to the size of the parastyle, which is large in D. antunesi; while the orientation of the preprotocrista relies more on the general lingual width of the upper molars (i.e. wide in D. ilicis and D. gigasei). Again, for these characters, D. antunesi is closer to Asian taxa, D. indicus and D. pakistanensis (Kumar et al., 2010: fig. 8), which present a lingual shift of the preprotocrista on M1, and a relatively narrow lingual lobe on the upper molars. Based on upper molar morphology, we agree that $D$. gigasei and D. morrisi are closer to D. ilicis than to D. antunesi. Yet, for now, there is no formal way to affirm that these character state represent the primitive condition. Hooker (2010) uses outgroup comparison as polarization criterion, and compares Diacodexis species to hyopsodontids and arctocyonids. Hyopsodontids is a polyphyletic assemblage and might be more closely related to Perissodactyla or some afrotherians, than to Artiodactyla (Zack et al., 2005; Tabuce et al., 2007b; Ladevèze et al., 2010; Tabuce in press) and should be left aside. Arctocyonids show a wide range of morphologies, including a hypoconid closely apposed to the entoconid in lingual position on $\mathrm{m} 1-2$, and bulging entoconid (e.g., Chriacus truncatus Rose, 1996: fig. 1; Loxolophus hyattianus Kondrashov and Lucas, 2012). Arctocyonids also show a wide range of orientation of the M1-2 postprotocrista and "centrocrista bowing": Protungulatum and other arctocyonids (e.g., Rose, 2006: fig. 12.3) exhibit a lingual shift of the preparacrista and a strong parastyle, related to a 
"bowed centrocrista". This is a plesiomorphic condition at the eutherian scale (e.g., Wible et al., 2009). The generally simple molar crown morphology of most arctocyonids, with high and pointed cusps associated with the primitive tribosphenic-tritubercular pattern, recall a somewhat more "insectivorous" diet. Still, this morphology could as well be secondarily derived within Artiodactyla, but in the general picture of Paleocene/Eocene eutherians, would be consistent with a primitive pattern in $D$. antunesi.

The new material described here further documents the premolar dentition of European Diacodexis species and provides new morphological characters for comparisons. The $\mathrm{P} 4$ of $D$. antunesi, is morphologically close to $D$. pakistanensis with a labial wall with no ectoflexus, and a paracone with salient endoparacristule. This structure is absent in D. gigasei, and in the specimen referred to $D$. aff. antunesi from Fordones; it is also lacking in D. ilicis. The P4 of D. gigasei presents an ectoflexus, like North American species like D. ilicis (Fig. 7), D. secans-metsiacus (Krishtalka and Stucky, 1985: fig. 4D-E).), or D. secans-secans (Krishtalka and Stucky, 1985: fig. 2A-B). The P3 of European species is rather short anteroposteriorly and bears a wide paracone; the lingual lobe of $D$. aff antunesi is small and poorly differentiated, and bears no accessory cusp. This lobe is larger and more individualized in Diacodexis sp. from La Borie, with a small accessory cusp. P3 of European species are closer morphologically to the P3 of D. indicus from Vastan, than to the P3 of North American species D. ilicis and D. secans metsiacus, which are longer anteroposteriorly and slenderer bucco-lingually with a more salient lingual bobe and a bigger accessory cusp. Regarding the lower dentition, the $\mathrm{p} 4$ of $D$. aff. gigasei from Palette is closer to D. ilicis than to D. indicus. Unfortunately, comparisons with $D$. antunesi are not possible as this locus is not documented yet. The morphology of the dp4 is complex and each documented taxon has its specificity (see above). 

D. antunesi, in accordance with Gingerich (1989), Smith et al. (1996), and Hooker (2010).

Diacodexis antunesi, and D. aff. antunesi from Fordones appear to be morphologically closer to the Asiatic taxa D. indicus and D. pakistanensis. As a result, if a cladistic analysis of these taxa appears premature, an interesting conclusion may nevertheless be drawn at this stage: although $D$. antunesi and $D$. gigasei are certainly very close in age, close to the PETM, the preceding comparisons show that these two European species differ widely. This strongly suggests that at least two phases of migration of Diacodexis could have occurred in Europe around the Paleocene-Eocene boundary. Asia might be the dispersal centre of these two events (see Beard 1998). Interestingly, an Asian origin of European Diacodexis might be supported by the similarities between $D$. antunesi and the Asian species D. pakistanensis and D. indicus. Such a faunal interchange between Europe and South Asia, but well after the Paleocene-Eocene boundary, is also well-supported by some recent evidence (e.g., Smith et al. 2007; Rana et al. 2008; Rose et al. 2009; Tabuce et al. 2009).

Finally, we found numerous similarities between $D$. cf. gigasei from Palette and $D$. gigasei from Dormaal. This result is quite surprising considering the now well-established intra-European provincialism that characterizes the earliest Ypresian: mammals from the northwestern (Anglo-Belgian and Paris basins) and southwestern (south of France and Iberian Peninsula) provinces greatly differ (Marandat, 1997; Marandat et al., 2012; Solé et al., 2017). Along with few species — such as the herpetotheriid marsupial Peratherium constans and the paromomyid plesiadapiform Arcius fuscus (see Godinot et al. 1987; López-Torres and Silcox in press) - D. gigasei could be one of the rare species in common between northwestern and southwestern bioprovinces.

\section{Conclusions}



Diacodexis species, including the earliest representatives of the genus. Documentation of the enamel microstructure of Diacodexis antunesi from Silveirinha and Diacodexis aff. antunesi from Fordones, reveals that those early species had a simple enamel pattern with one-layered Schmelzmuster composed of 'basic' radial enamel only. These observations contrast with those performed on North American species that present a two-layered Schmelzmuster composed of a thin layer of radial enamel and a thick layer of Hunter-Schreger bands. This latter enamel microstructure pattern was so far considered to represent the primitive condition within Artiodactyla. The occurrence of a simple one-layer enamel in earliest European Diacodexis species challenges this hypothesis, and rather suggests that this simple pattern represents the primitive condition among Diacodexis species and probably among Artiodactyla. Likewise, the crown morphology of the dp4 of earliest Diacodexis species indicates a considerable diversity of the tooth occlusal pattern. Some Diacodexis species from Europe have only one anterior cuspid, two basins, and present an hourglass outline instead of the trilobed pattern so far considered as a synapomorphy for Artiodactyla. Besides, the dp4 of Diacodexis bear two pillars only, which contrasts with the three rooted pattern of other artiodactyls considered to be more derived. Study of earliest Diacodexis species therefore questions features considered as primitive within Artiodactyla. A large scale revision of diacodexeid species including North American material, as well as a wide sampling of potential branching groups, would be necessary to discuss the early radiation of Artiodactyla through a formal cladistic analysis, and properly determine character polarization.

In accordance with previous study, our observations highlight that Diacodexis gigasei is morphologically closer to $D$. ilicis than to $D$. antunesi. The latter species, together with the new material referred to $D$. aff. antunesi from Fordones, appear to be morphologically closer to the Asiatic taxa D. indicus and D. pakistanensis. Finally, we found numerous similarities 
between D. cf. gigasei from Palette and D. gigasei from Dormaal, a result that attenuates the intra-European provincialism that characterizes the earliest Ypresian. Diacodexis gigasei could be one of the rare species in common between northwestern and southwestern bioprovinces.

\section{Acknowledgements}

We are grateful to A.-L. Charuault (ISEM, Montpellier, France) for having prepared the mandible from Palette and to J. Clavel (IBENS, Paris, France) for providing us with photographs from the Silveirinha material. We are also grateful to the Rougier family, who facilitated field work in Palette. We thank L. Alloing-Séguier (ISEM) and S. Enault (ISEM) for their advices regarding enamel microstructure protocol and taking images. Data presented in this work were produced through the technical facilities of the MRI platform and of the labEx CeMEB. We warmly thank Chantal Cazevieille (Montpellier RIO Imaging, Institut des Neurosciences de Montpellier, France) for granting access to a scanning electron microscope facility. We are grateful to the Terreal Society, especially L. Nathan for his assistance during the excavations.

\section{References}

Alloing-Séguier, L., Lihoreau, F., Boisserie, J. R., Charruault, A. L., Orliac, M., Tabuce, R., 2014. Enamel microstructure evolution in anthracotheres (Mammalia, Cetartiodactyla) and new insights on hippopotamoid phylogeny. Zoological Journal of the Linnean Society, 171(3), 668-695.

Antunes, M.T., Russell, D.E., 1981. Le gisement de Silveirinha (Bas mondego, portugal) : la plus ancienne faune de Vertébrés éocènes connue d'Europe. Comptes Rendus de l'Académie des Sciences II 293, 1099-1102.

Antunes, M.T., Casanovas, M.L., Cuesta, M.A., Checa, L., Santafé, J.V., Agustí, J., 1997. Eocene mammals from Iberian Peninsula. Mémoires et travaux de l'Institut de Montpellier, 21, 337-352. 
Averianov, A., 1996. Artiodactyla from the early Eocene of Kyrgyzstan. Palaeovertebrata, 25(2-4), 359-369.

Bajpai, S., Kapur, V.V., Das, D.P., Tiwari, B.N., Saravanan, N., Sharma, R., 2005. Early Eocene land mammals from the Vastan lignite mine, district Surat (Gujarat), Western India. Journal of The Palaeontological Society of India 50 (1), 101-113.

Beard, K.C., 1998. East of eden: Asia as an important center of taxonomic origination in mammalian evolution. Bulletin of Carnegie Museum of Natural History 34, 5-39.

Biochrom'97. 1997. Synthèses et tableaux de corrélations, in : Aguilar, J.P., Legendre, S., Michaux, J. (Eds.), Actes du congrès international de biochronologie mammalienne Biochrom' 97. Mémoires et travaux de l'institut de Montpellier, Ecole Pratique des Hautes Etudes 21. Montpellier, 1997, pp. 765-805.

Boisserie, J.-R., Lihoreau, F., Orliac, M.J., Fisher, R., Weston, E., Ducrocq, S., 2009. Morphology and phylogenetic relationships of the earliest known hippopotamids (Cetartiodactyla, Hippopotamidae, Kenyapotaminae). Zoological Journal of the Linnean Society, 158, 325-367.

Bowen, G.J., Maibauer, B.J., Kraus, M.J., Rölh, U., Westerhold, T., Steimke, A., Gingerich, P.D., Wing, S.L., Clyde, W.C., 2015. Two massive, rapid releases of carbon during the onset of the Palaeocene-Eocene thermal maximum. Nature Geoscience, 8, 44-47.

Checa Soler, L.C., 2004. Revisión del género Diacodexis (Artiodactyla, Mammalia) en el Eoceno inferior del Noreste de España. Geobios, 37(3), 325-335.

Cope, E.D., 1882. The oldest artiodactyl. American Naturalist, 16, 61.

Estravis, C., Russell, D.E., 1989. Découverte d'un nouveau Diacodexis dans l'Eocène inférieur de Silveirinha, Portugal. Palaeovertebrata, 19 (1), 29-44.

Estravis, C., 1992. Estudo dos mamíferos do Eocénico inferior de Silveirinha (Baixo Mondego). Universidade Nova de Lisboa, Lisbon, p. 248.

Estravis, C., 2000. Nuevos mamiferos del Eoceno inferior de Silveirinha (Baixo Mondego, Portugal). Coloquios de Paleontologia 51, 281-311.

Gatesy, J., Geisler, J. H., Chang, J., Buell, C., Berta, A., Meredith, R. W., et al., 2013. A phylogenetic blueprint for a modern whale. Molecular phylogenetics and evolution, 66(2), 479-506.

Geisler, J.H., Chang, J., Buell, C., Berta, A., Meredith, R.W., Springer, M.S., McGowen, M.R., 2013. A phylogenetic blueprint for a modern whale. Molecular phylogenetics and evolution $66,479-506$. 
Geisler, J.H., 2001. New morphological evidence for the phylogeny of Artiodactyla, Cetacea, and Mesonychidae. American Museum Novitates, 1-53.

Geisler J.H., Theodor, J.M., 2009. Hippopotamus and whale phylogeny. Nature, 468 (7236), e1-e4.

Gentry, A.W., Hooker, J.J., 1988. The phylogeny of the Artiodactyla, in: Benton, M.J. (Ed.), The phylogeny and classification of the tetrapods, Volume 2: Mammals. Systematics Association, Clarendon press, Oxford, pp. 235-272.

Gingerich, P.D., 1989. New earliest Wasatchian mammalian fauna from the Eocene of the Northwestern Wyoming: composition and diversity in a rarely sampled high-floodplain assemblage. University of Michigan, Papers on Paleontology, 28, 1-97.

Gingerich, P.D., Russell, D.E., Sigogneau-Russell, D., Hartenberger, J.L., 1979. Chorlakkia hassani, a new middle Eocene dichobunid (Mammalia, Artiodactyla) from the Kuldana Formation of Kohat (Pakistan). Contributions from the Museum of Paleontology, The University of Michigan, 25(6), 117-124.

Gingerich, P.D., 2006. Environment and evolution through the Paleocene-Eocene thermal maximum. Trends in Ecology and Evolution, 21, 246-253.

Gingerich, P.D., 1989. New earliest Wasatchian mammalian fauna from the Eocene of northwestern Wyoming: composition and diversity in a rarely sampled high-floodplain assemblage. Papers on paleontology, 28, 1-97.

Godinot, M., 1981. Les mammifères de Rians (Eocène inférieur, Provence). Palaeovertebrata, 10(2), 43-126.

Godinot, M., 1984. Un nouveau genre de Paromomyidae (Primates) de l'Eocène inférieur d'Europe. Folia Primatologica 43, 84-96.

Godinot, M., Crochet, J.-Y., Hartenberger, J.-L., Lange-Badré, B., Russell, D.E., Sigé, B., 1987. Nouvelles données sur les mammifères de Palette (Eocène inférieur, Provence), in: Schmidt-Kittler, N. (Ed.), International Symposium on Mammalian Biostratigraphy and Paleoecology of the European Paleogene. Verlag Friedrich Pfeil, pp. 273-288.

Guthrie, D.A., 1971. The mammalian fauna of the Lost Cabin Member, Wind River Formation (Lower Eocene) of Wyoming. Annals of Carnegie Museum, 43(4), 47-90. Hooker, J.J., 2010. The mammal fauna of the early Eocene Blackheath Formation of Abbey Wood, London. Palaeontographical Society Monographs 634 (164), 1-162.

Koenigswald, W.V., Rensberger, J.M., Pfretzschner, U., 1987. Changes in the tooth enamel of early Paleocene mammals allowing increased diet diversity. Nature, 328, 150-152. 
Kondrashov, P.E., Lucas, S.G., 2012. Nearly Complete Skeleton of Tetraclaenodon (Mammalia, Phenacodontidae) from the Early Paleocene of New Mexico: MorphoFunctional Analysis. Journal of Paleontology, 86 (1), 25-43.

Krishtalka, L., Stucky, R.K., 1985. Revision of the Wind river Faunas, early Eocene of central Wyoming, revision of Diacodexis (mammalia, artiodactyla). Ann.als of the Carnegie Museum 54, 413-486.

Kumar, K., Jolly, A., 1986. Earliest artiodactyl (Diacodexis, Dichobunidae: Mammalia) from the Eocene of Kalakot, northwestern Himalaya, India. Indian Society of Geology Bulletin, 2, 20-30.

Kumar, K., Rose, K.D., Rana, R.S., Singh, L., Smith, T., Sahni, A., 2010. Early Eocene artiodactyls (Mammalia) from western India. Journal of Vertebrate Paleontology, 30(4), $1245-1274$.

Ladevèze, S., Missiaen, P., Smith, T., 2010. First skull of Orthaspidotherium edwardsi (Mammalia, "Condylarthra") from the late Paleocene of Berru (France) and phylogenetic affinities of the enigmatic European family Pleuraspidotheriidae. Journal of Vertebrate Paleontology, 30(5), 1559-1578.

Laurent, Y., Adnet, S., Bourdon, E., Corbalan, D., Danilo, L., Duffaud, S., Fleury, G., Garcia, G., Godinot, M., Le Roux, G., Maisonnave, C., Métais, E., Mourer-Chauviré, C., Presseq, B., Sigé, B., Solé, F., 2010. La Borie (Saint-Papoul, Aude) : un gisement exceptionnel dans l'Éocène basal du Sud de la France. Bulletin de la Société d'Histoire Naturelle de Toulouse 146, 89-103.

Luckett, W.P., Hong, N., 1998. Phylogenetic relationships between the orders Artiodactyla and Cetacea: a combined assessment of morphological and molecular evidence. Journal of Mammalian Evolution, 5(2), 127-182.

López-Torres, S., Silcox, M., in press. The European Paromomyidae (Primates, Mammalia): taxonomy, phylogeny, and biogeographic implications. Journal of Paleontology.

Maas, M.C., Thewissen, J.G.M., 1995. Enamel microstructure of Pakicetus (Mammalia: Archaeoceti). Journal of Paleontology, 69, 1154-1163.

Made, J. van der., 1996. Listriodontinae (Suidae, Mammalia), their evolution, systematics and distribution in time and space. Mededelingen van de Werkgroep voor Tertiaire en Kwartaire Geologie, 33(1/4), 3-254.

Marandat, B., 1991. Mammifères de l'Ilerdien moyen (Eocène inférieur) des Corbières et du Minervois (Bas-Languedoc, France). Systématique, Biostratigraphie, corrélations. Palaeovertebrata, 20(2-3), 55-144. 
Marandat, B., Adnet, S., Marivaux, L., Martinez, A., Vianey-Liaud, M., Tabuce, R., 2012. A new mammalian fauna from the earliest Eocene (Ilerdian) of the Corbières (Southern France): palaeobiogeographical implications. Swiss Journal of Geosciences, 105(3), 417-434.

Missiaen, P., Quesnel, F., Dupuis, C., Storme, J.-Y. \& Smith, T., 2013. The earliest Eocene mammal fauna of the Erquelinnes Sand Member near the French-Belgian border. Geologica Belgica, 16(4): 262-273.

Nel, A., Ploeg G.D., Dejax, J., Dutheil, D., Fransceschi, D.D., Gheerbrant, E., Godinot, M., Hervet, S., Menier, J.-J., Augé, M., Bignot, G., Cavagnetto, C., Duffaud, S., Gaudant, J., Hua, S., Jossang, A., Lapparent de Broin, F.D., Pozzi, J.-P., Paicheler, J.-C., Beuchet, F., Rage, J.-C., 1999. Un gisement sparnacien exceptionnel à plantes, arthropodes et vertébrés (Eocène basal, MP7) : Le Quesnoy (Oise, France). Comptes Rendus de l'Académie des Sciences, Paris 329: 65-72.

Orliac, M.J., Ducrocq, S., 2012. Eocene raoellids (Mammalia, Cetartiodactyla) outside the Indian Subcontinent: palaeogeographical implications. Geological Magazine, 149(01), 80-92.

Orliac, M.J., Gilissen, E., 2012. Virtual endocranial cast of earliest Eocene Diacodexis (Artiodactyla, Mammalia) and morphological diversity of early artiodactyl brains. Proceedings of the Royal Society of London B: Biological Sciences, 279(1743), 36703677.

Orliac, M.J., O’Leary, M.A., 2014. Comparative anatomy of the petrosal bone of dichobunoids, early members of Artiodactylamorpha (Mammalia). Journal of Mammalian Evolution, 21(3), 299-320.

Orliac, M. J., Karadenizli, L., Antoine, P. O., Sen, S., 2015. Small hyotheriine suids (Mammalia, Artiodactyla) from the late Early Miocene of Turkey and a short overview of Early Miocene small suoids in the Old World. Palaeontologia Electronica, 18(2), 118.

Orliac, M.J., Boivin, M., Tabuce, R., in press. A mandible of Diacodexis cf. gigasei (Artiodactyla, Diacodexeidae) from the early Eocene locality of Palette (Bouches-duRhône, France). MorphoMuseuM.

Rana, R.S., Kumar, K., Escarguel, G., Sahni, A., Rose, K.D., Smith, T., Singh, H., Singh, L., 2008. An ailuravine rodent from the lower Eocene Cambay Formation at Vastan, western India, and its palaeobiogeographic implications. Acta Palaeontologica Polonica $53,1-14$. 
Robinet, C., Remy, J.A., Laurent, Y., Danilo, L., Lihoreau, F., 2015. A new genus of Lophiodontidae (Perissodactyla, Mammalia) from the early Eocene of La Borie (Southern France) and the origin of the genus Lophiodon Cuvier, 1822. Geobios, 48(1), $25-38$.

Romer, A.S., 1966. Vertebrate paleontology, $3^{\text {rd }}$ ed. University of Chicago Press, Chicago.

Rose, K.D., 1982. Skeleton of Diacodexis oldest Known artiodactyl. Science, 216(4546), $621-623$.

Rose, K.D., 1996. On the origin of the order Artiodactyla. Proceedings of the National Academy of Sciences, 93(4), 1705-1709.

Rose, K.D., 2006. Archaic ungulates. The beginning of the age of mammal. John Hopkins university press, Baltimore.

Rose, K.D., Chew, A.E., Dunn, R.H., Kraus, M.J., Fricke, H.C., Zack, S.P., 2012. Earliest Eocene mammalian fauna from the Paleocene-Eocene thermal maximum at Sand Creek divide, Southern Bighorn Basin, Wyoming. University of Michigan, Papers in Paleontology, 36, 1-122.

Rose, K.D., Rana, R.S., Sahni, A., Kumar, K., Singh, L., Smith, T., 2009. First tillodont from India: Additional evidence for an early Eocene faunal connection between Europe and India? Acta Palaeontologica Polonica 54, 351-355.

Russell, D.E., Thewissen, J.G.M., Sigogneau-Russel, D., 1983. A new dichobunoid artiodactyl (Mammalia) from the Eocene of North-West Pakistan - II Cranial osteology. Proceedings of the Koninklijke Nederlandse Akademie van Wetenschappen, Series B, 3, 285-300.

Sigogneau-Russell, D., Russell, D.E., 1983 A new dichobunoid artiodactyl (Mammalia) from the Eocene of North-West Pakistan - III Reconstitution du moulage endocrânien. Proceedings of the Koninklijke Nederlandse Akademie van Wetenschappen, Series B, 3, 319-330.

Smith, T., Rana, R.S., Missiaen, P., Rose, K.D., Sahni, A., Singh, H., Singh, L., 2007. High bat (Chiroptera) diversity in the early Eocene of India. Naturwissenschaften 94, 10031009.

Smith, T., Rose, K.D., Gingerich, P.D., 2006. Rapid Asia-Europe-North America geographic dispersal of earliest Eocene primate Teilhardina during the Paleocene-Eocene thermal maximum. Proceedings of the National Academy of Sciences, 103(30), 11223-11227. 
Smith, R., Smith, T., Sudre, J., 1996. Diacodexis gigasei n. sp., le plus ancien Artiodactyle (Mammalia) belge, proche de la limite Paléocène-Eocène. Bulletin de l'Institut Royal des Sciences Naturelles de Belgique, Sciences de la Terre, 66, 177-186.

Solé, F., J., F., Laurent, Y., 2014. New proviverrines (Hyaenodontida) from the early Eocene of Europe; phylogeny and ecological evolution of the Proviverrinae. Zoological Journal of the Linnean Society 171, 878-917.

Solé, F., Smith, T., Tabuce, R., Marandat, B., 2017. New dental elements of the oldest proviverrine, Parvagula palulae, from the early Eocene of Southern France and their support for a possible African origin of the Proviverrinae (Hyaenodonta, Mammalia). Acta Palaeontologica Polonica 60, 527-538.

Stefen, C., 1999. Evolution of enamel microstructure of archaic ungulates ("Condylarthra") and comments on some other early Tertiary mammals. Paleobios, 19, 15-36.

Sudre, J., Russell, D., Louis, P., Savage, D.E., 1983. Les Artiodactyles de l'Eocène inférieur d'Europe. I. Bulletin du Muséum National d'Histoire Naturelle. Section C, Sciences de la terre, paléontologie, géologie, minéralogie, 5(3), 281-333.

Sudre, J., Erfurt, J., 1996. Les artiodactyles du gisement yprésien terminal de Prémontré (Aisne, France). Palaeovertebrata, 25(2-4), 391-414.

Tabuce, R., Delmer, C., Gheerbrant, E., 2007a. Evolution of the tooth enamel microstructure in the earliest proboscideans (Mammalia). Zoological Journal of the Linnean Society, 149(4), 611-628.

Tabuce, R., Marivaux, L., Adaci, M., Bensalah, M., Hartenberger, J.-L., Mahboubi, M., Mebrouk, F., Taffoeau, P., Jaeger, J.-J., 2007b. Early Tertiary mammals from North Africa reinforce the molecular Afrotheria clade. Proceedings of the Royal Society B: Biological Science, 274, 1159-1166.

Tabuce, R., Seiffert, E.R., Gheerbrant, E., Alloing-Séguier, L., Koenigswald, W. von., 2017. Tooth enamel microstructure of living and extinct hyracoids reveals unique enamel types among mammals. Journal of Mammalian Evolution, 24, 91-110.

Tabuce, R., Antunes, M.T., Smith, R., Smith, T., 2006. Dental and tarsal morphology of the European Paleocene/Eocene “condylarth” mammal Microhyus. Acta Palaeontologica Polonica 51, 37-52.

Tabuce, R., Antunes, M.T., Sigé, B., 2009. A new primitive bat from the earliest Eocene of Europe. Journal of Vertebrate Paleontology 29, 627-630. 
Tabuce, R., Clavel, J., Antunes, M.T., 2011. A structural intermediate between triisodontids and mesonychians (Mammalia, Acreodi) from the earliest Eocene of Portugal. Naturwissenschaften 98, 145-155.

Tabuce, R., in press. - New remains of Chambius kasserinensis from the Eocene of Tunisia and evaluation of proposed affinities for Macroscelidea (Mammalia, Afrotheria). Historical Biology.

Theodor, J.M., Erfurt, J., Métais, G., 2007. The earliest artiodactyls, in: Prothero, D.R., Foss, S.E. (Eds). The evolution of Artiodactyla. Johns Hopkins university press, Baltimore, pp. 32-58.

Thewissen, J.G.M., Russell, D.E., Gingerich, P.D., Hussain, S.T., 1983. A new dichobunid artiodactyl (Mammalia) from the Eocene of north-west Pakistan. Proceedings of the Koninklijke Nederlandse Akademie van Wetenschappen, Series B, 86(2), 153-180.

Van Valen, L.M., 1971. Toward the origin of artiodactyls. Evolution, 25(3), 523-529.

Wible, J.R., Rougier, G.W., Novacek, M.J., Asher, R.J., 2009. The eutherian mammal Maelestes gobiensis from the Late Cretaceous of Mongolia and the phylogeny of Cretaceous Eutheria. Bulletin of the American Museum of Natural History, 327, 1-123.

Yans, J., Marandat, B., Masure, E., Serra-Kiel, J., Schnyder, J., Storme, J.-Y., Marivaux, L., Adnet, S., Vianey-Liaud, M., Tabuce, R., 2014. Refined bio- (benthic foraminifera, dinoflagellate cysts) and chemostratigraphy ( $\delta 13 \mathrm{Corg})$ of the earliest Eocene at AlbasLe Clot (Corbières, France): implications for mammalian biochronology in Southern Europe. Newsletters on Stratigraphy 47, 331-353.

Zack, S.P., Penkrot, T.A., Krause, D.W., Maas, M.C., 2005. A new apheliscine 'condylarth' mammal from the Late Paleocene of Montana and Alberta and the phylogeny of'hyopsodontids'. Acta Palaeontologica Polonica, 50(4), 809-830. 


\begin{tabular}{|l|l|l|l|l|}
\hline Tooth & Specimen & L & l & L/I \\
\hline $\mathbf{p}$ & UM SNC 386 & 2.83 & 1.05 & 2.71 \\
\hline $\mathbf{p}$ & UM SNC 64 & 2.91 & 0.93 & 3.13 \\
\hline $\mathbf{m 1}$ & UM SNC 93 & 2.68 & 1.74 & 1.54 \\
\hline $\mathbf{m 1}$ & UM SNC 6 & 2.65 & 1.89 & 1.40 \\
\hline $\mathbf{m 1}$ & UM SV3-133 & 3.05 & 2.00 & 1.53 \\
\hline $\mathbf{m 1}$ & UM SNC 74 & 2.72 & 1.76 & 1.55 \\
\hline $\mathbf{m 2}$ & UM SNC 74 & 3.07 & 2.12 & 1.45 \\
\hline $\mathbf{m 2}$ & UM SV3-338 & 3.43 & 2.14 & 1.60 \\
\hline $\mathbf{m 2}$ & UM SNC 3 & 3.13 & 2.44 & 1.28 \\
\hline $\mathbf{m 3}$ & UM SV3-129 & 4.27 & 2.59 & 1.65 \\
\hline $\mathbf{m 3}$ & UM SV3-332 & 3.50 & 2.34 & 1.49 \\
\hline $\mathbf{m 3}$ & UM SNC 63 & 3.51 & 2.02 & 1.74 \\
\hline $\mathbf{m 3}$ & UM SNC 17 & 3.72 & 2.34 & 1.59 \\
\hline $\mathbf{m 3}$ & UM SNC 65 & 3.71 & 2.24 & 1.66 \\
\hline $\mathbf{P 3}$ & UM SNC 58 & 3.27 & 1.79 & 1.83 \\
\hline $\mathbf{P 4}$ & UM SNC 33 & 2.43 & 2.97 & 0.82 \\
\hline $\mathbf{P 4}$ & UM SNC 311 & 2.49 & 3.08 & 0.81 \\
\hline $\mathbf{P 4}$ & UM SNC 405 & 2.32 & 3.38 & 0.69 \\
\hline $\mathbf{d P 4}$ & UM SNC 13 & 3.15 & 3.24 & 0.97 \\
\hline dP4 & UM SV3-131 & 2.91 & 2.58 & 1.13 \\
\hline $\mathbf{M 1}$ & UM SNC 49 & 2.86 & 4.03 & 0.71 \\
\hline $\mathbf{M 1}$ & UM SV3-163 & 2.72 & 3.45 & 0.79 \\
\hline $\mathbf{M 1}$ & UM SV3-189 & 2.66 & 3.40 & 0.78 \\
\hline $\mathbf{M 1}$ & UM SV3-128 & 2.97 & 3.70 & 0.80 \\
\hline $\mathbf{M 1}$ & UM SNC 339 & - & $3.59 *$ & - \\
\hline $\mathbf{M 2}$ & UM SV3-74 & 3.07 & 4.11 & 0.75 \\
\hline $\mathbf{M 2}$ & UM SNC 20 & 3.07 & 3.79 & 0.81 \\
\hline $\mathbf{M 2}$ & UM SNC 25 & 2.98 & 3.79 & 0.79 \\
\hline $\mathbf{M 2}$ & UM SNC 36 & 3.15 & 3.95 & 0.80 \\
\hline $\mathbf{M 2}$ & UM SNC 55 & 3.27 & 4.11 & 0.80 \\
\hline $\mathbf{M 2}$ & UM SNC 95 & 3.50 & 4.02 & 0.87 \\
\hline $\mathbf{M 3}$ & UM SNC 18 & 2.38 & 3.20 & 0.74 \\
\hline $\mathbf{M 3}$ & UM SNC 262 & 2.52 & 3.34 & 0.75 \\
\hline $\mathbf{M 3}$ & UM SV3-126 & 3.16 & 3.65 & 0.87 \\
\hline & & & & \\
\hline
\end{tabular}

1260 Table 1. Dental measurements of the new material of Diacodexis antunesi from Silveirinha,

1261 Portugal described in this work. Abbreviations: L, maximal length; 1, maximal width, * corresponds to estimated value on broken material. 


\begin{tabular}{|l|c|c|c|}
\hline Locality & Silveirinha & Palette & Palette \\
\hline specimen & UM SNC 687 & UM PAT 168 & UM PAT 19 \\
\hline Length (L) & - & 7.08 & 6.90 \\
\hline Width body (l1) & 4.17 & 4.15 & 3.76 \\
\hline Width neck (12) & 2.31 & 2.62 & 2.57 \\
\hline Width head (13) & - & 3.68 & 3.68 \\
\hline Length head (L3) & - & 2.33 & 2.05 \\
\hline Length sust. fac. (Ls) & 2.85 & 3.57 & 3.54 \\
\hline Width sust. fac. (ls) & 2.02 & 2.16 & 2.42 \\
\hline Width navic. fac. $(\mathbf{l n})$ & - & 2.44 & 2.37 \\
\hline
\end{tabular}

Table 2. Measurements of the astragalus from the MP7 localities of Silveirinha and Palette.

\begin{tabular}{|l|l|c|c|c|}
\hline tooth & specimen & L & l & L/l \\
\hline $\mathbf{p}$ & UM FDN 279 & 2.80 & 1.25 & 2.25 \\
\hline dp4 & UM FDN 123 & 3.51 & 1.61 & 2.18 \\
\hline $\mathbf{m 1}$ & UM FDN 255 & 3.19 & 2.312 & 1.38 \\
\hline $\mathbf{m 1}$ & UM FDN 124 & 3.27 & 2.20 & 1.49 \\
\hline $\mathbf{m 2}$ & UM FDN 125 & 3.57 & 2.88 & 1.20 \\
\hline $\mathbf{P 2}$ & UM FDN 252 & - & 1.33 & 2.07 \\
\hline P3 & UM FDN 251 & 3.30 & 2.34 & 1.41 \\
\hline $\mathbf{P 3}$ & UM FDN 283 & 2.89 & 2.03 & 1.42 \\
\hline $\mathbf{P 4}$ & UM FDN 283 & 2.39 & 2.75 & 0.87 \\
\hline $\mathbf{M 2}$ & UM FDN 283 & 3.12 & 4.13 & 0.76 \\
\hline M3 & UM FDN 283 & 2.82 & 3.71 & 0.76 \\
\hline
\end{tabular}

1268 Table 3. Dental measurements of Diacodexis aff. antunesi from Fordones, France. .

1269 Abbreviations: L, maximal length; 1, maximal width. 


\begin{tabular}{|l|l|c|c|c|}
\hline tooth & specimen & L & I & L/l \\
\hline $\mathbf{m 1 - m 3}$ & UM PAT 159 & 11.23 & - & - \\
\hline $\mathbf{p 4 - m 3}$ & UM PAT 159 & 14.93 & - & - \\
\hline $\mathbf{p 3 - m 3}$ & UM PAT 159 & 18.55 & - & - \\
\hline $\mathbf{c ~ ( a l v e o l u s ) ~}$ & UM PAT 159 & 2.13 & 0.93 & - \\
\hline $\mathbf{p 1 ~ ( a l v e o l u s ) ~}$ & UM PAT 159 & 2.29 & 1.02 & - \\
\hline $\mathbf{p 2}$ (alveolus) & UM PAT 159 & 3.42 & 1.21 & - \\
\hline $\mathbf{p 3}$ & UM PAT 159 & 3.74 & 1.60 & 2.34 \\
\hline $\mathbf{p 4}$ & UM PAT 159 & 3.79 & 2.04 & 1.86 \\
\hline $\mathbf{m 1}$ & UM PAT 159 & 3.02 & 2.43 & 1.25 \\
\hline $\mathbf{m 1}$ & UM PAT 136 & 3.23 & 2.16 & 1.50 \\
\hline $\mathbf{m 2}$ & UM PAT 159 & 3.58 & 2.96 & 1.21 \\
\hline $\mathbf{m 3}$ & UM PAT 159 & 4.63 & 2.91 & 1.59 \\
\hline
\end{tabular}

1272 Table 4. Dental measurements of Diacodexis cf. gigasei from Palette, France. Abbreviations:

1273 L, maximal length; 1, maximal width.

\begin{tabular}{|l|l|c|c|c|}
\hline tooth & specimen & L & I & L/I \\
\hline $\mathbf{m 1}$ & UM APSO.2015.SP2-302 & 4.20 & 2.83 & 1.48 \\
\hline P3 & UM BRI1 & 3.30 & 2.40 & 1.37 \\
\hline P4 & UM BRI2 & 2.76 & 3.04 & 0.91 \\
\hline M2 & UM BRI3 & 3.69 & - & - \\
\hline M3 & UM BRI4 & 2.67 & 4.08 & 0.65 \\
\hline
\end{tabular}

1276 Table 5. Dental measurements of Diacodexis sp. from La Borie, France. Abbreviations: L,

1277 maximal length; 1 , maximal width. 


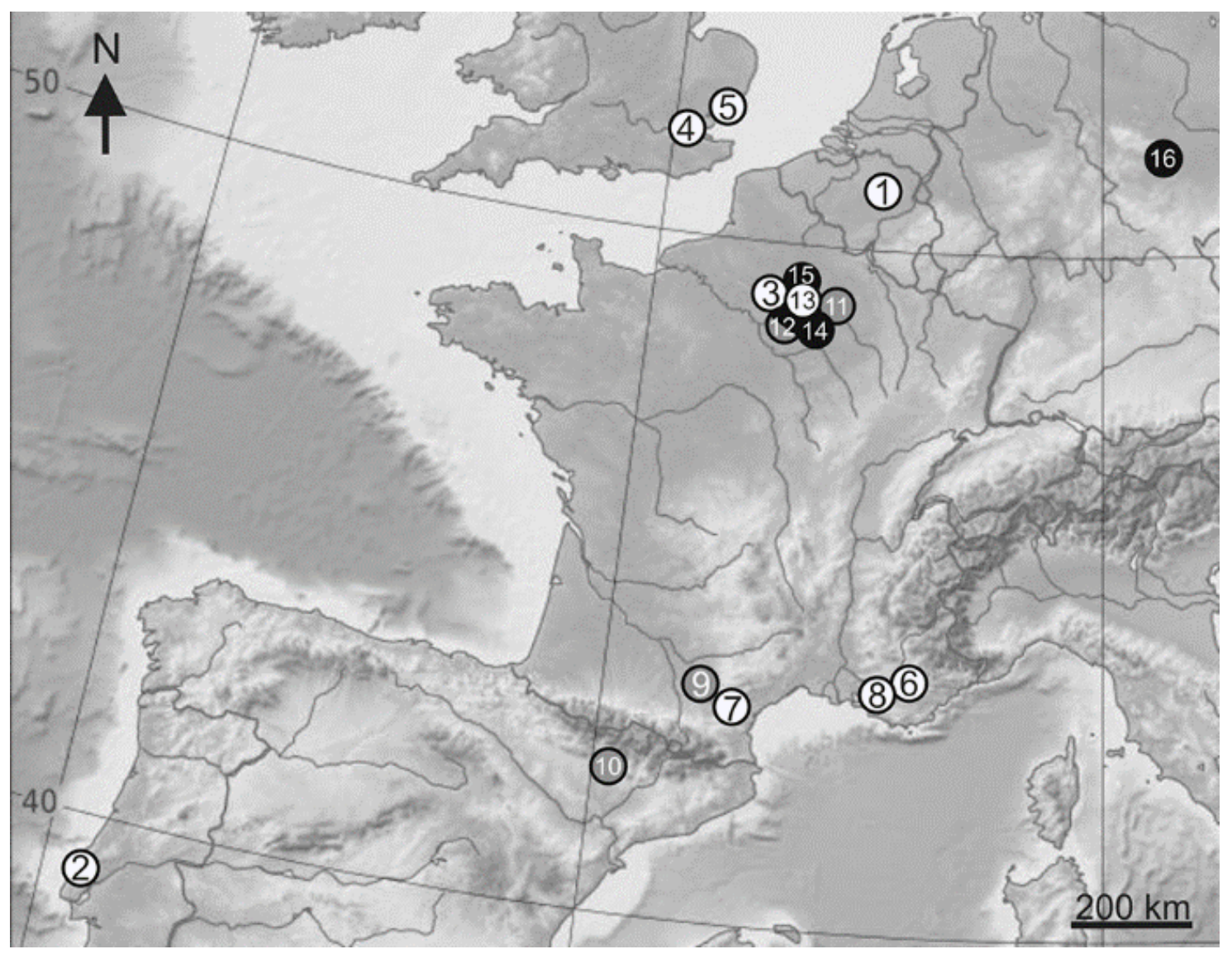

1281 Figure 1. Map showing early Eocene Diacodexis-bearing localities in Europe (MP7, MP8+9, 1282 and MP10 localities are indicated by white, grey, and black circles, respectively): 1- Dormaal, 1283 Belgium; 2-Silverinia, Portugal; 3-Le Quesnoy, France; 4- Abbey Wood, UK; 5-Kyson, UK; 1284 6-Rians, France; 7-Fordones, France; 8- Palette, France; 9-La Borie, France; 10- Corsà 0, 1285 Spain; 11-Avenay and Mutigny, France; 12-Condé-en-Brie and Saint-Agnan, France; $13-$ 1286 Pourcy, France; 14-Grauves, Cuis, and Mancy, France; 15-Prémontré, France; 16- Geiseltal, 1287 Germany. 


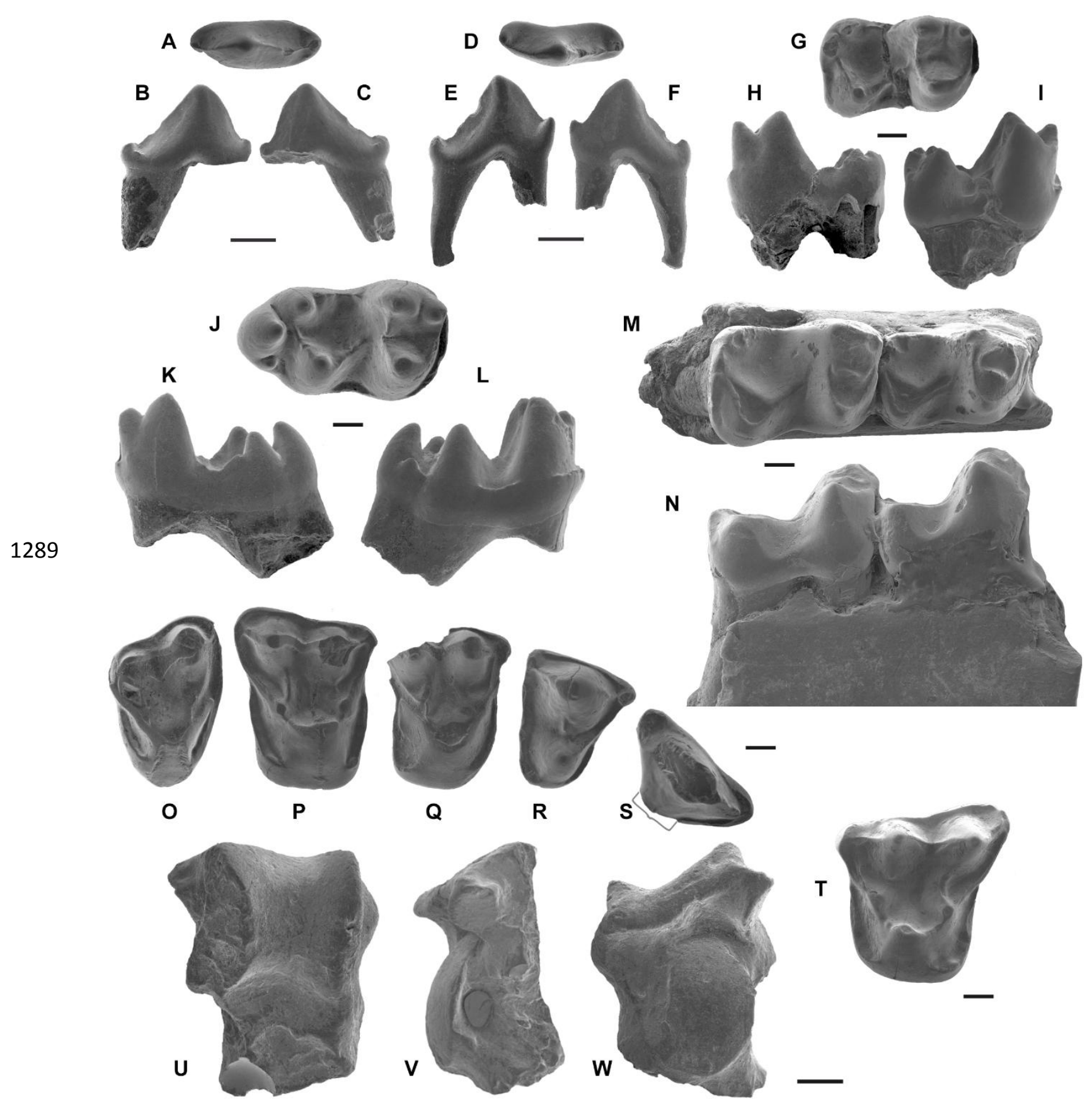

Figure 2. Dental and postcranial remains of D. antunesi from Silveirinha Pequena, Baixo

Mondego, Portugal. A-C, SNC 64, p2/3?; D-F SNC 386, dp2/3?; G-I SNC 93, m1; J-L, SNC 63, m3; M-N, SNC 74, m1-2; O, SNC 18, M3; P, SNC 20, M2; Q, SNC 339, M1; R, SNC 

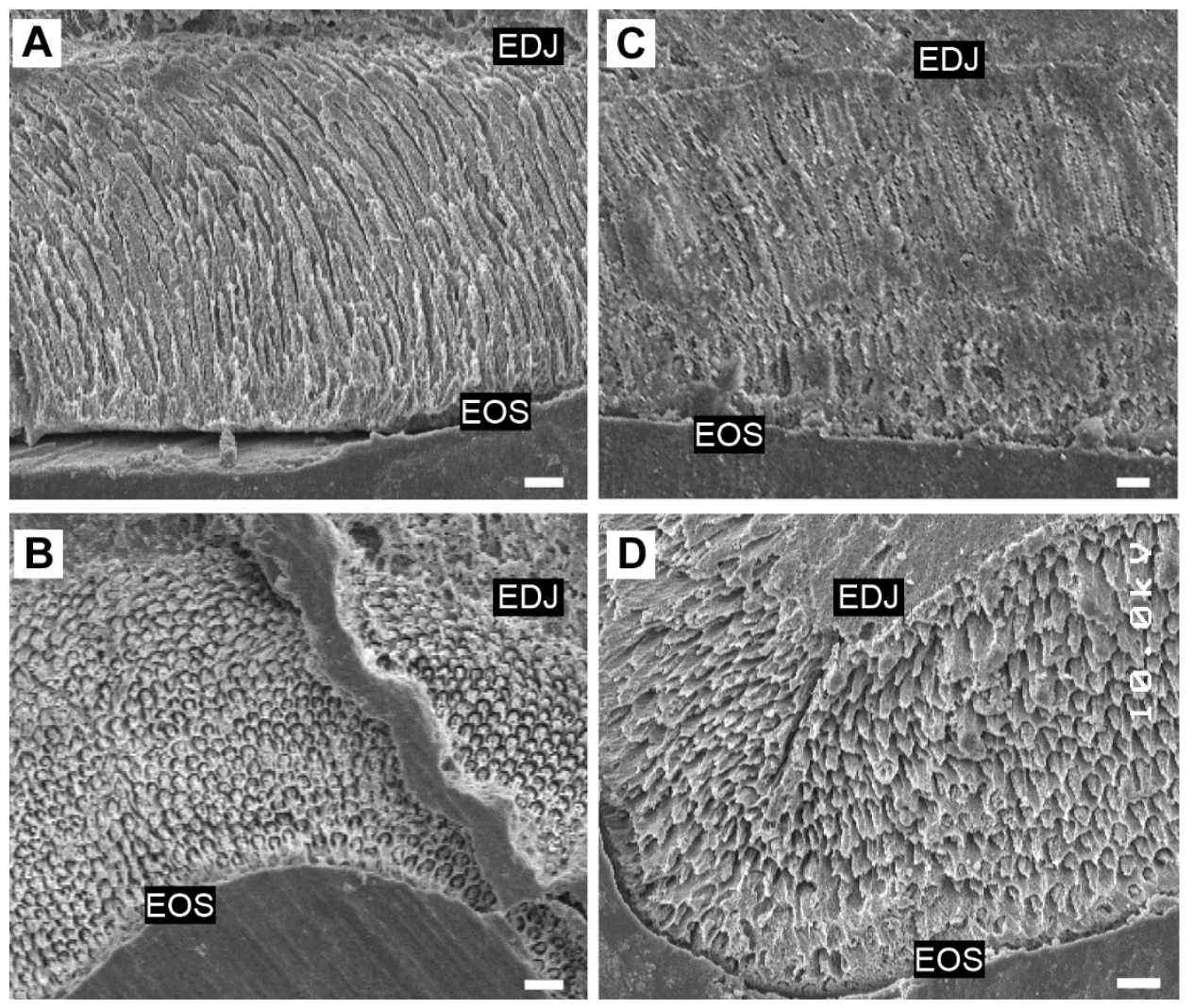

1298 Figure 3. Enamel microstructure in A-B, D. antunesi from Silveirinha Pequena, Baixo

1299 Mondego, Portugal and C-D, D. aff. antunesi from Fordones, Aude, France A-C horizontal 1300 plane, B-D tangential plane. Scale bar $=10 \mu \mathrm{m}$. 

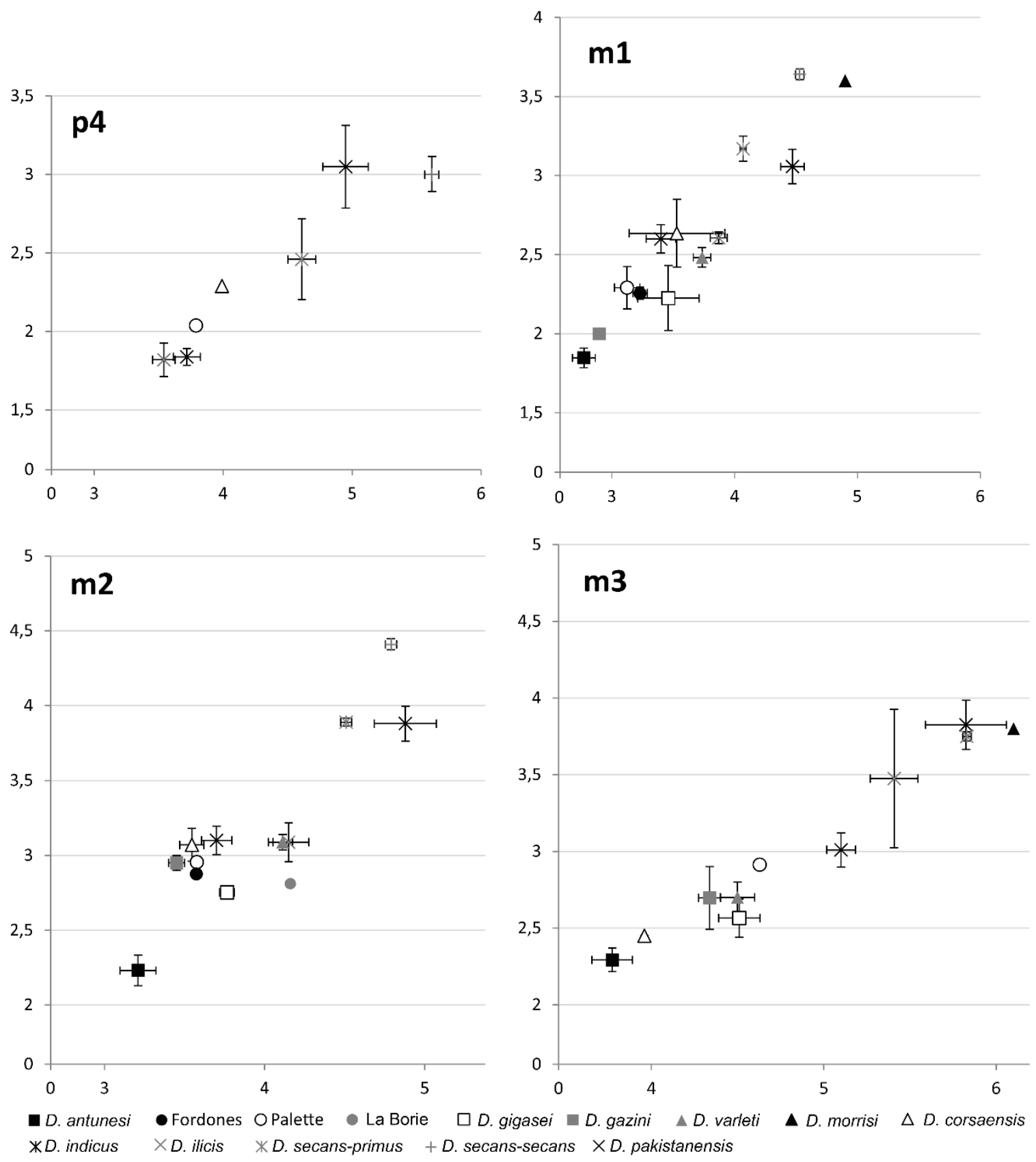

Figure 4. Biplots of lower dentition measurements with standard error. $X=$ length, $Y=$ width.

Measurements from: D. antunesi, Estravis and Russell (1989) and Table 1; Fordonnes, Marandat (1991) and Table 3; Palette, Table 4; La Borie, Table 5; D. gigasei, Smith et al. (1996); D. gazini, Godinot (1981); D. varleti, Sudre et al. (1983); D. morrisi, Hooker (2010); D. corsaensis, Checa Soler (2004); D. indicus, Kumar et al. (2010); D. ilicis, Gingerich (1989) and Rose et al. (2012); D. secans primus, Krishtalka and Stucky (1985); D. secans secans, Krishtalka and Stucky (1985); D. pakistanensis, Thewissen et al. (1983). 

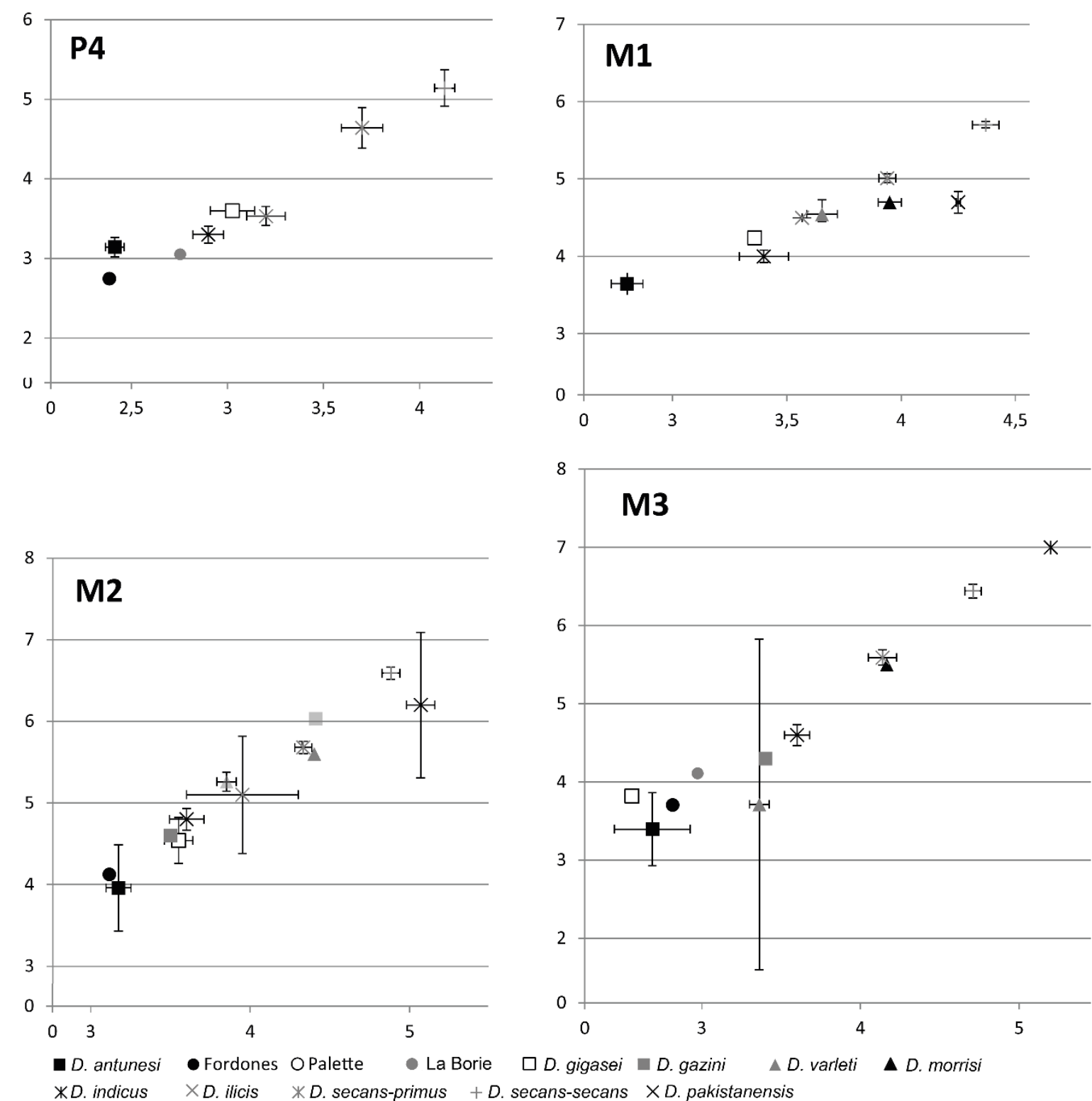

1311 Figure 5. Biplots of upper dentition measurements with standard error. $\mathrm{X}=$ length, $\mathrm{Y}=$ width.

1312 Measurements from: D. antunesi, Estravis and Russell (1989) and Table 1; Fordonnes,

1313 Marandat (1991) and Table 3; Palette, Table 4; La Borie, Table 5; D. gigasei, Smith et al.

1314 (1996); D. gazini, Godinot (1981); D. varleti, Sudre et al. (1983); D. morrisi, Hooker (2010);

D. corsaensis, Checa Soler (2004); D. indicus, Kumar et al. (2010); D. ilicis, Gingerich

1316 (1989) and Rose et al. (2012); D. secans primus, Krishtalka and Stucky (1985); D. secans

1317 secans, Krishtalka and Stucky (1985); D. pakistanensis, Thewissen et al. (1983). 

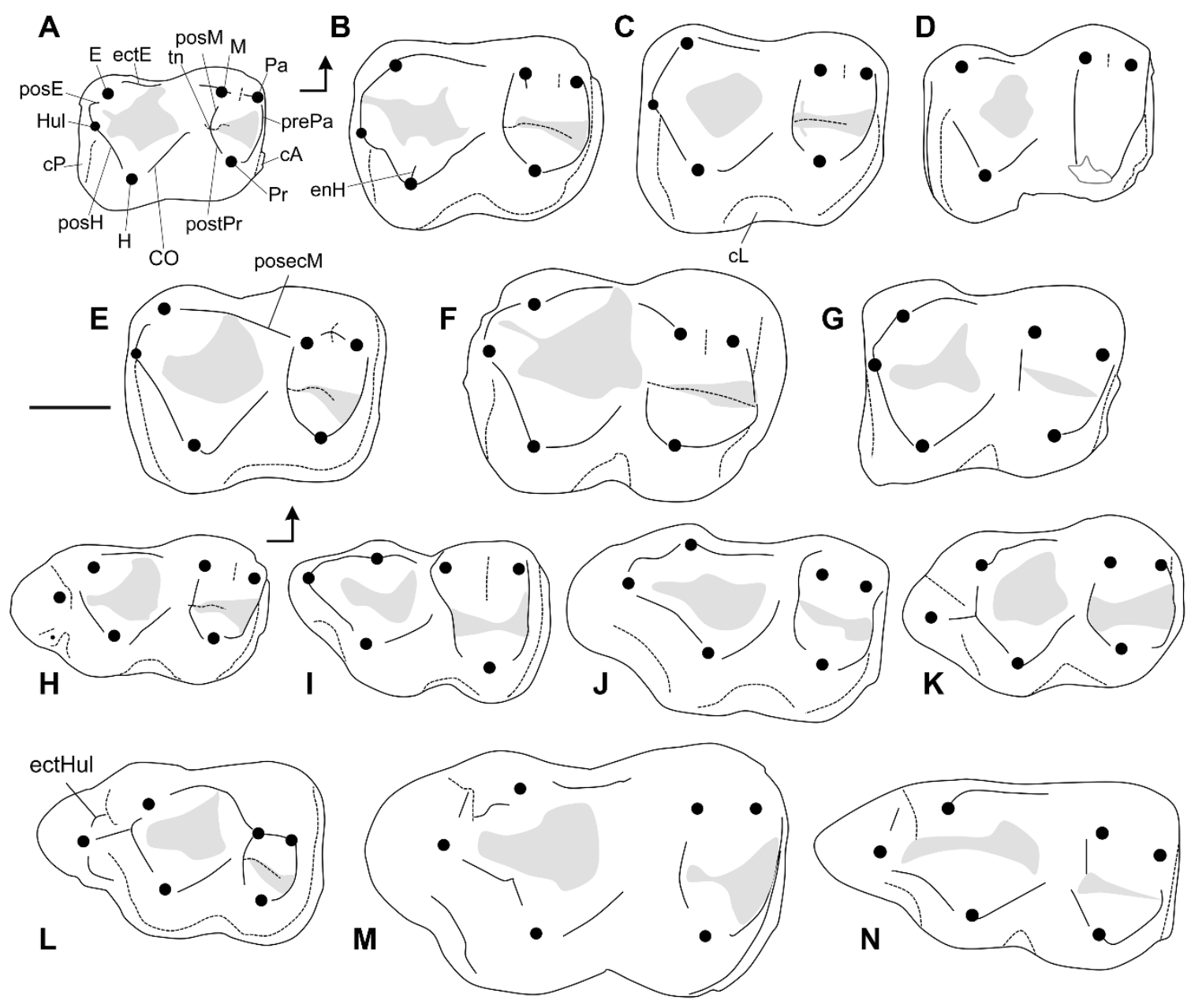

Figure 6. Lower dentition of Diacodexis species. A-G m2 of: A, D. antunesi SV3 338; B, D. gigasei IRScNB M 1815; C: D. cf. gigasei PAT 152; D: D. aff. antunesi FDN 125; E, D. gazini RI 163; F: D. varleti CB 1276, G: D. pakistanensis HGSP 300 5003. H-N, m3s: H, D. antunesi SNC 63; I, D. gigasei IRScNB M 116; J, D. cf. gigasei PAT 152; K, D. varleti CB 579; L, D. gazini RI 162; M: D. morrisi M60060; N, D. pakistanensis HGSP 3005003. Abbreviations: $\mathrm{cP}$, posterior cingulid; $\mathrm{cL}$, labial cingulid; $\mathrm{cM}$, mesial cingulid; $\mathrm{CO}$, cristid 1326 obliqua (= prehypocristid); ectE, ectoentocristid; ectHul, ectohypocristulid; enH, 1327 endohypocristid; E, entoconid; H, hypoconid; Hul, hypoconulid; M, metaconid; Pa, 1328 paraconid; posecM, postectometacristid; posE, postentocristid; posH, posthypocristid; posM, 

notch. Modified after Kumar et al. (2010) and Orliac \& Ducrocq (2011).

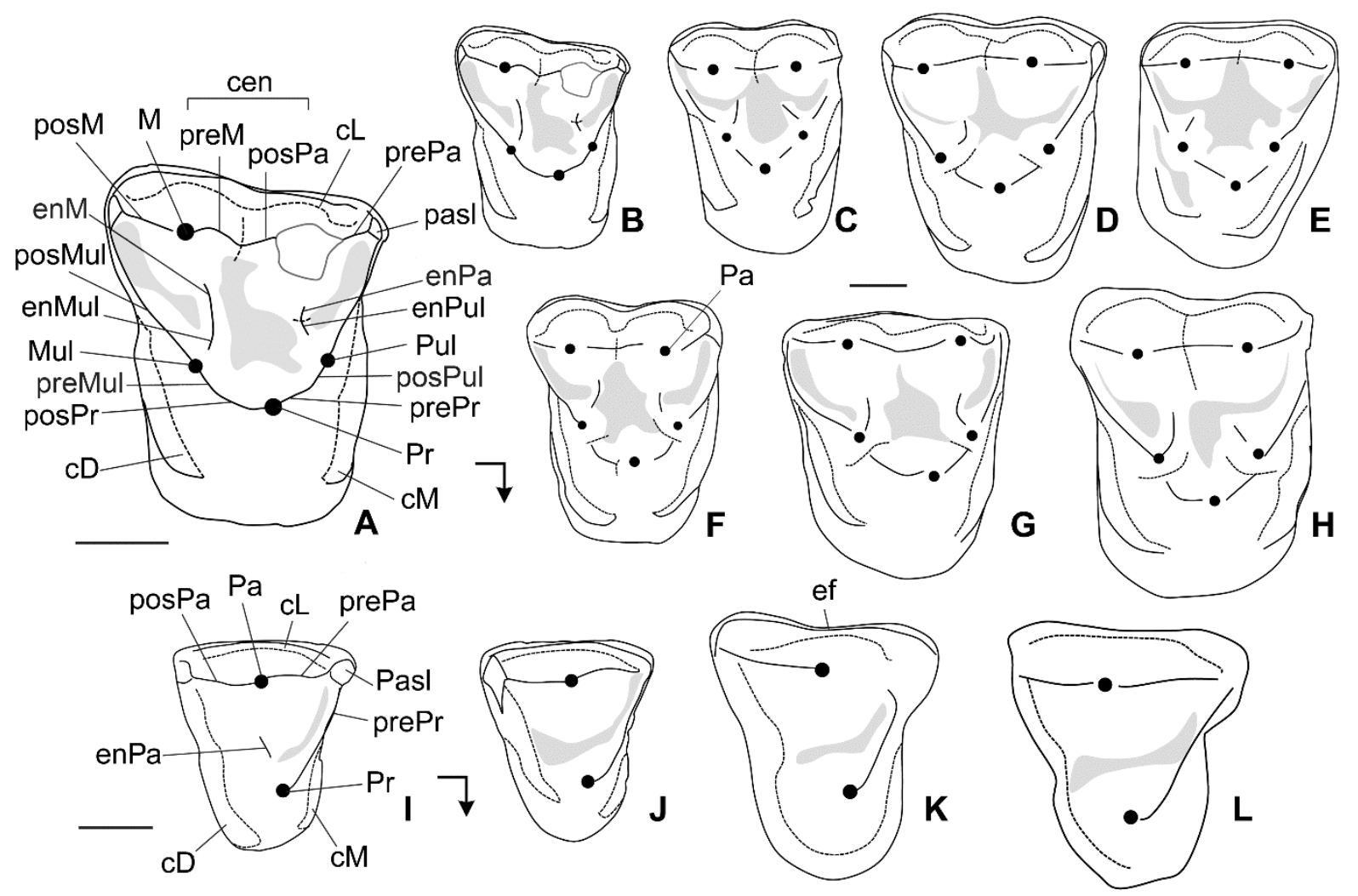

Figure 7. Upper dentition of Diacodexis species. A-H: M1 or M2 of: A-B, D. antunesi SNC 20; C, D. aff. antunesi FDN 283; D, D. varleti CB 973; E, D. gazini RI 168; F, D. gigasei IRScNB M 1820; G, D. morrisi M44943; H, D. ilicis USNM 538412. I-L: P4 of: I, D. antunesi SNC 311; J, D. aff. antunesi FDN 283; K, D. gigasei IRScNB M1822; L, D. ilicis USNM 538412. Abbreviation: cen, centrocrista; cD, distal cingulum; cL, labial cingulum; cM, mesial cingulum; ef, ectoflexus; enMul, endometacristule; enPr, endoprotocrista; enPul, endoprotocristule; M, metacone; Mul, metaconule; enPul, endoparacristule; $\mathrm{Pa}$, paracone; Pasl, parastyle; posPa, postparacrista; posM, postmetacrista; posMul, postmetacristule; posMuld, postmetacristule deflection; posPr, postprotocrista; prePa, preparacrista; prePr,

1341 preprotocrista; preM, premetacrista; prePr, preprotocrista; Pr, protocone; Pul, protoconule. Modified after Kumar et al. (2010) and Orliac \& Ducrocq (2011). 


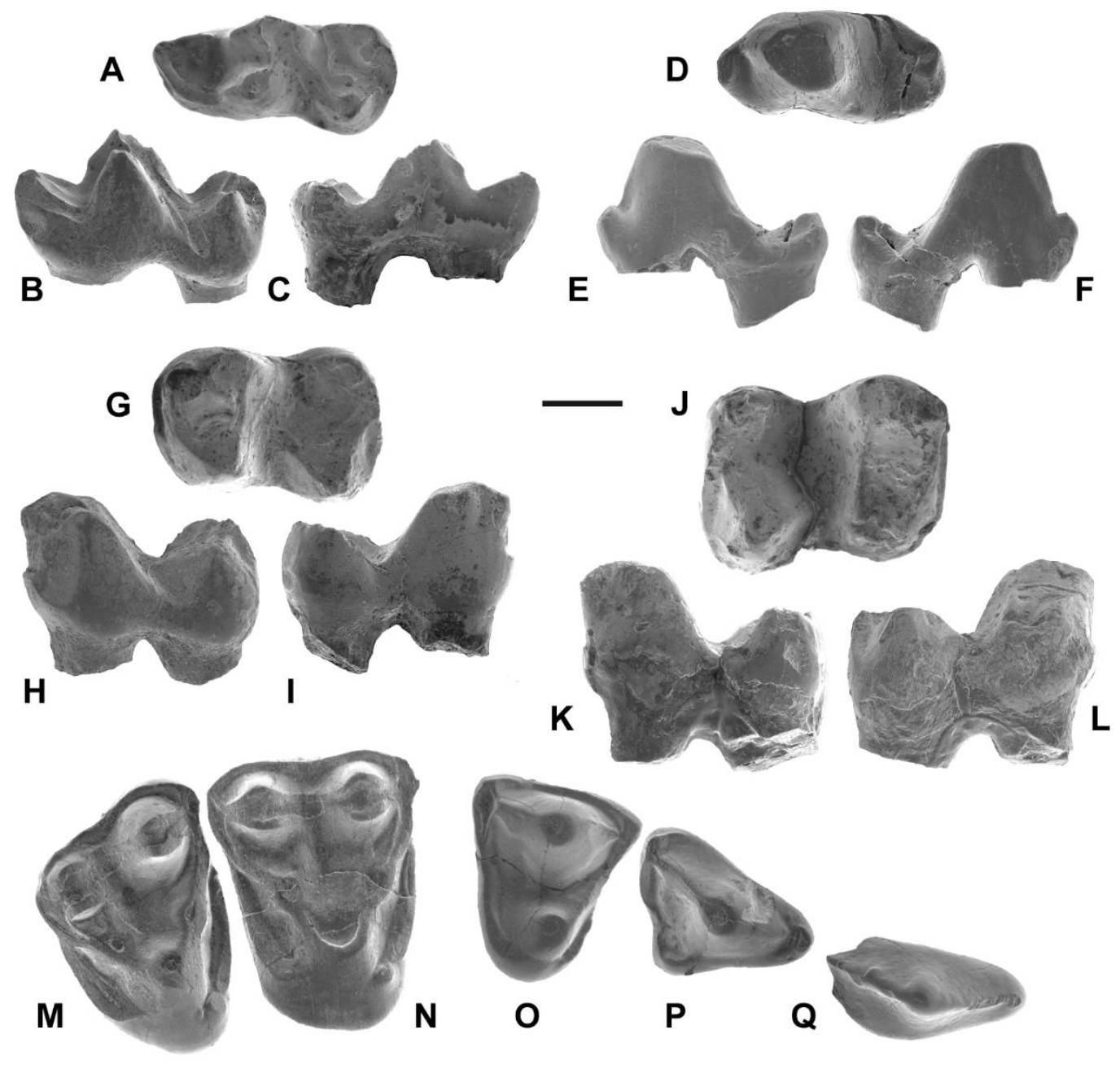

Figure 8. Dental remains of D. aff. antunesi from Fordones, Aude, France. A-C, FDN 123, 1346 dp4; D-F, FDN 279, p2 or p3; G-I, FDN 124, m1; J-L, FDN 125, m2; M-P, associated upper 1347 tooth row, from right to left M3, M2, P4, P3 (FDN 283); Q, P2 (FDN 252). All material 1348 figured at the same scale. Views: A, D, G, J, M-Q, occlusal; B, F, H, L, labial; C, E, I, K, 1349 lingual. Scale bar=1mm. 

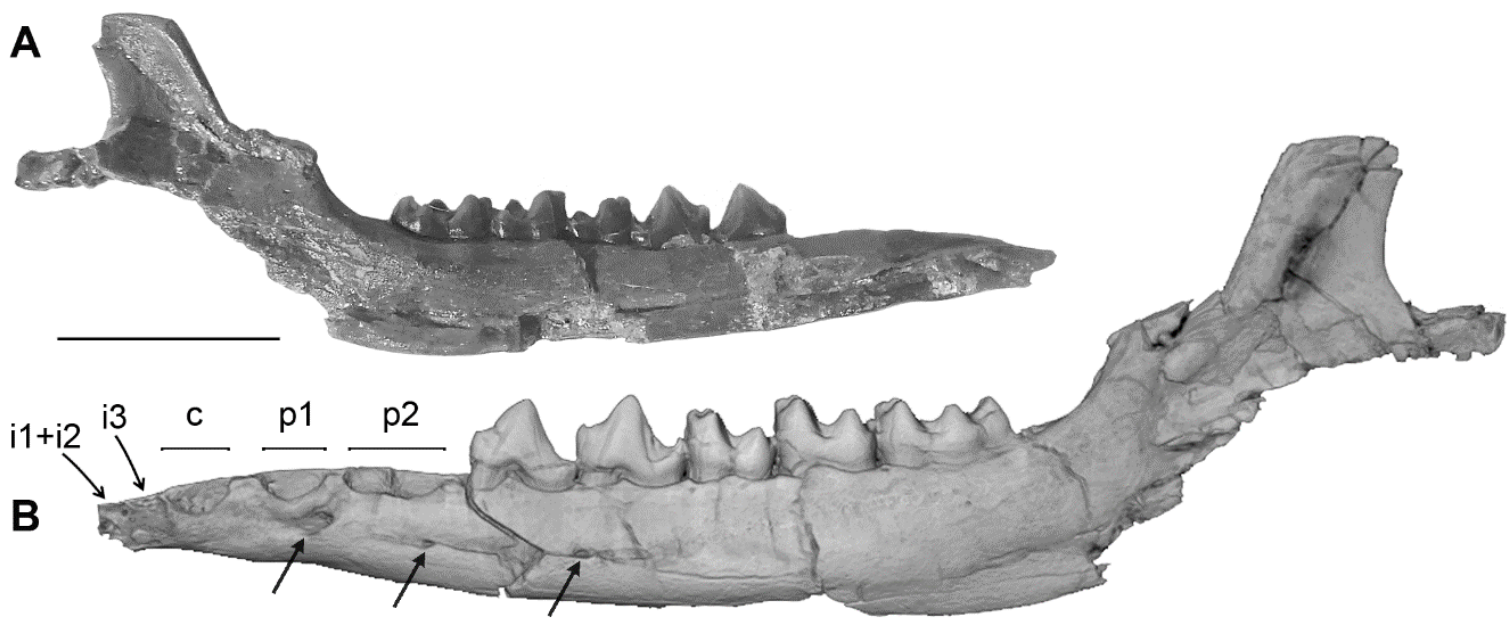

B
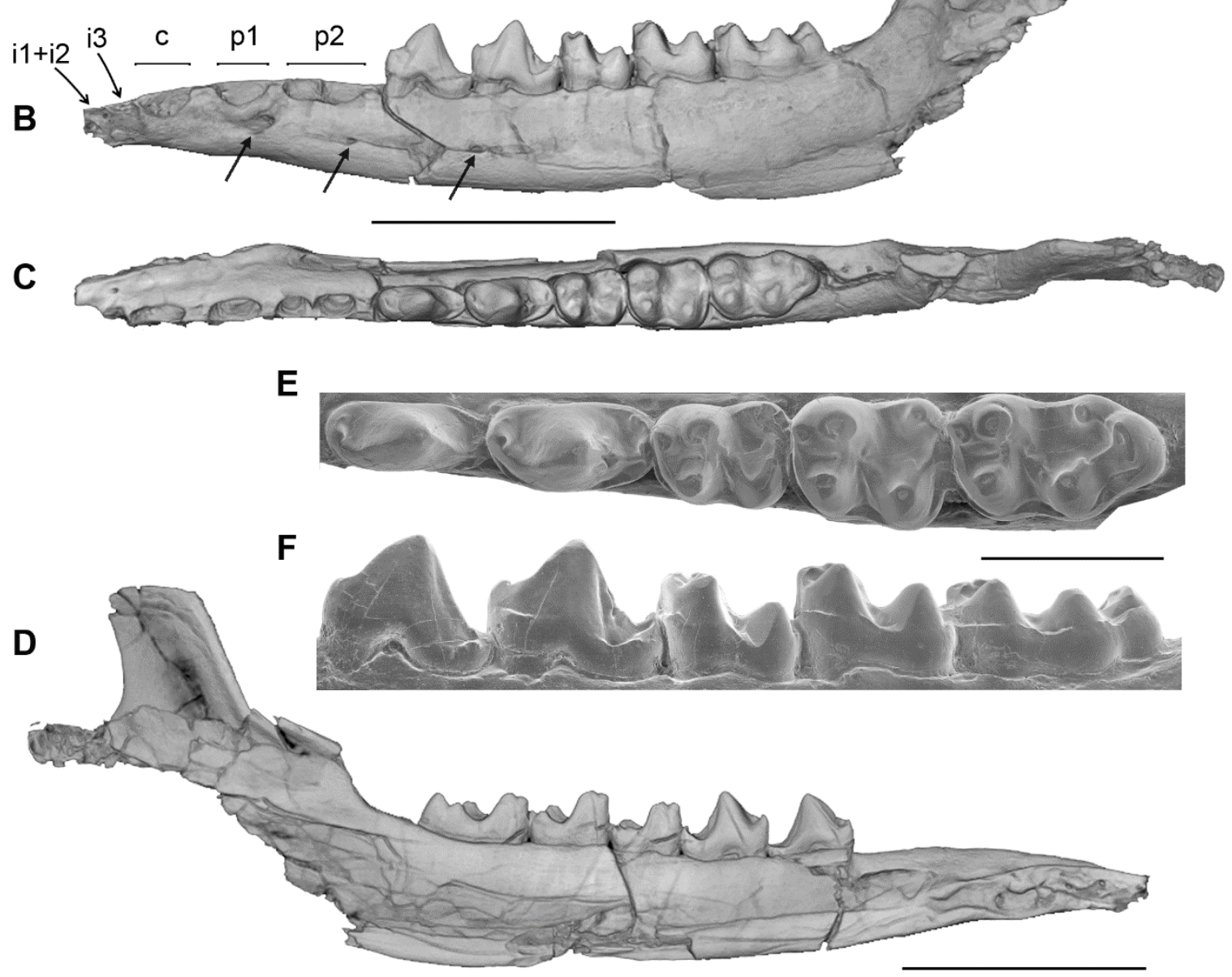

1352 Figure 9. Diacodexis cf. gigasei from Palette. A, PAT 159 medial view; B-D virtual 3D

1353 model of PAT 159 in B, medial, C, occlusal, D, lateral views; E-F, details of the teeth row in

1354 E, occlusal and F, labial view. Arrows indicate location of mental foramina. Scale bars $=1 \mathrm{~cm}$ 1355 for A-D, $5 \mathrm{~mm}$ for E-F. 

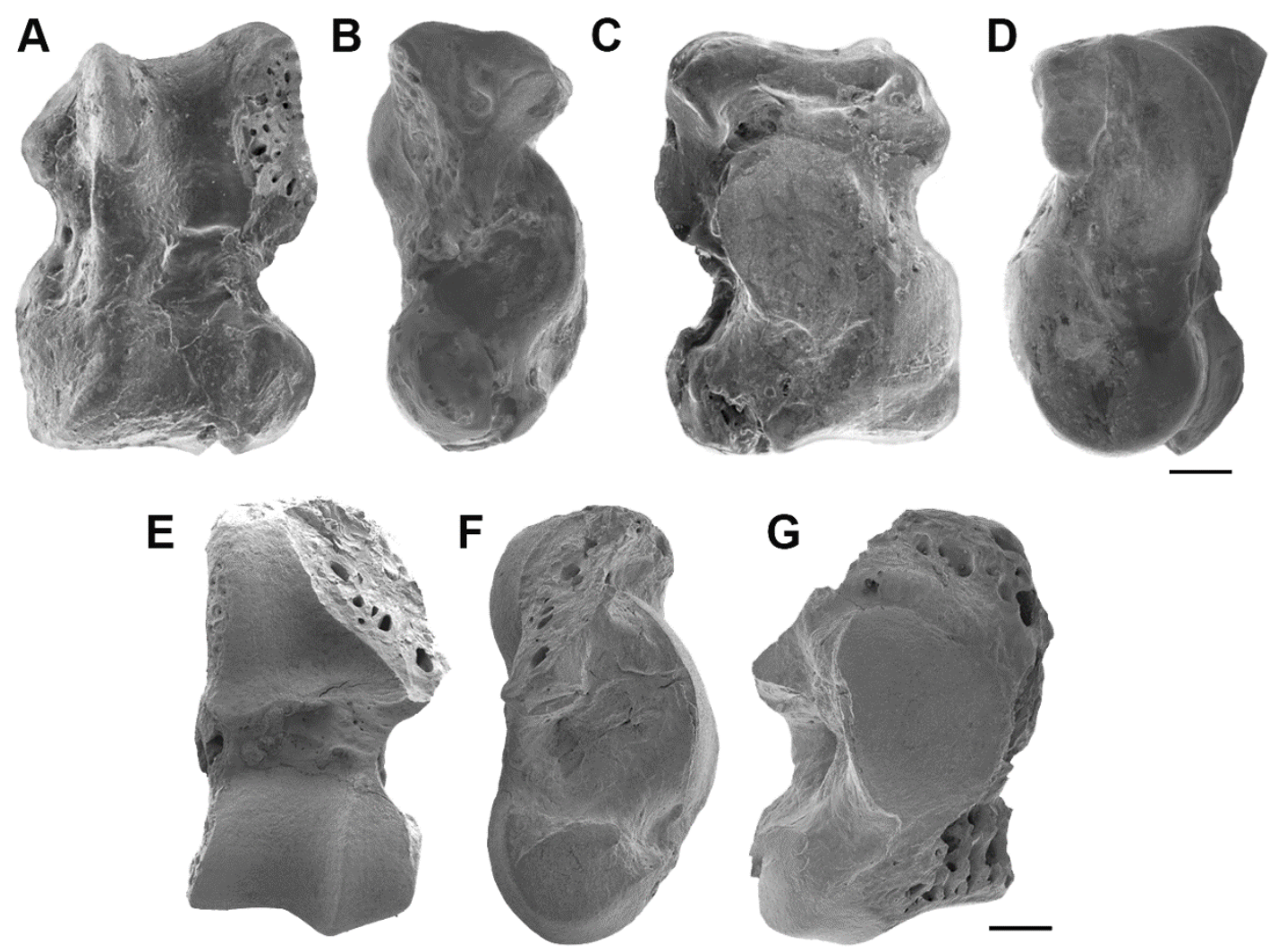

1358 Figure 10. Astragali of Diacodexis cf. gigasei from Palette. A-D, left astragalus (PAT 19) in 1359 A, anterior; B, lateral; C, posterior; D, medial views; E-G, right astragalus (PAT 168) mirror view, in E, anterior; F, lateral; G, posterior views. Scale bars $=1 \mathrm{~mm}$. 

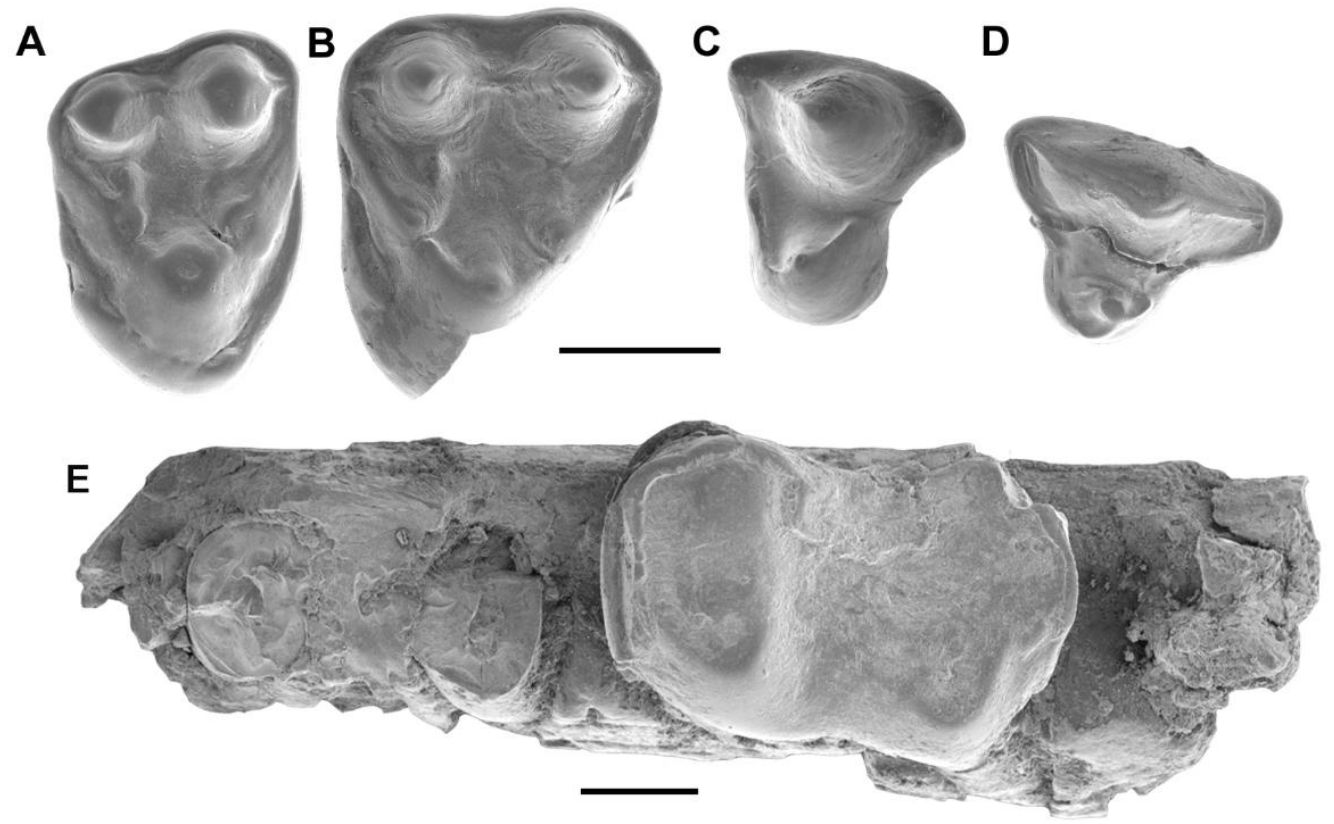

1363

1364 Figure 11. Dental remains of Diacodexis sp. from La Borie, Aude, France. A, BRI 4, M3; B,

1365 BRI 3, M2; C, BRI 2, P4; D, BRI 1, P3 ; E, MHNT.PAL.2017.21.2, m2 on a fragmentary

1366 dentary. Scale bars: A-D = $1.5 \mathrm{~mm} ; \mathrm{E}=1 \mathrm{~mm}$. 

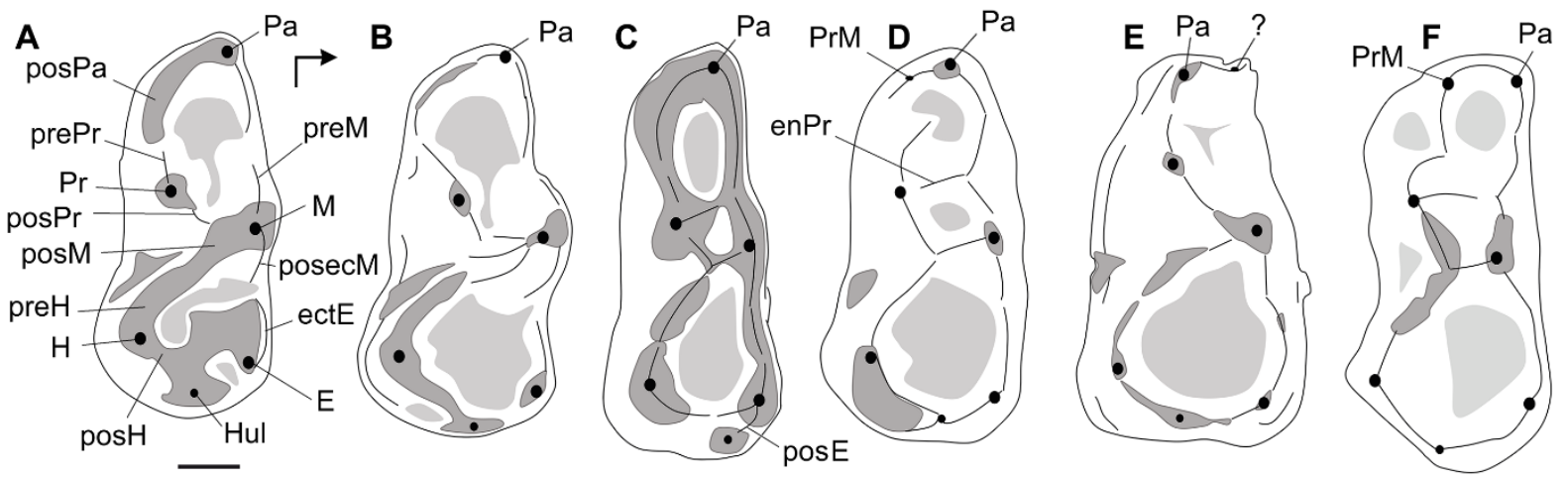

Figure 12. Schematic pattern of grooves and crests of the lower fourth deciduous premolar of

Diacodexeinae and Eurodexeinae. A, D. aff. antunesi (FDN 123); B, D. morrisi (M63703;

drawn after Hooker 2010:fig.48E); C, Diacodexis indicus (Gu 513; drawn after Kumar et al., 2010); D, Diacodexis sp. from Prémontré (UM PRE151); E, D. cf. varleti from Prémontré (SLP-29-PE 637) mentioned by Sudre and Erfürt (1996); F, Eurodexinae indet. from

Prémontré (SLP 29PR 2122) according to Sudre and Erfürt (1996). Scale bar $=0.5 \mathrm{~mm}$. Full

1375 lines originating from cuspids represent crests; dark grey surfaces represent worn surfaces;

1376 light grey surfaces represent basins. Abbreviations: ectE, ectoentocristid; E, entoconid; enPr,

1377 endoprotocristid; H, hypoconid; Hul, hypoconulid; M, metaconid; Pa, paraconid; posecM,

1378 postectometacristid; posE, postentocristid; posH, posthypocristid; posM, postmetacristid;

1379 posPa, postparacristid; posPr, postprotocristid; preH, prehypocristid; preM, premetacristid;

1380 prePa, preparacristitid; Pr, protoconid; prePr, preprotocristid; PrM, primonid. 

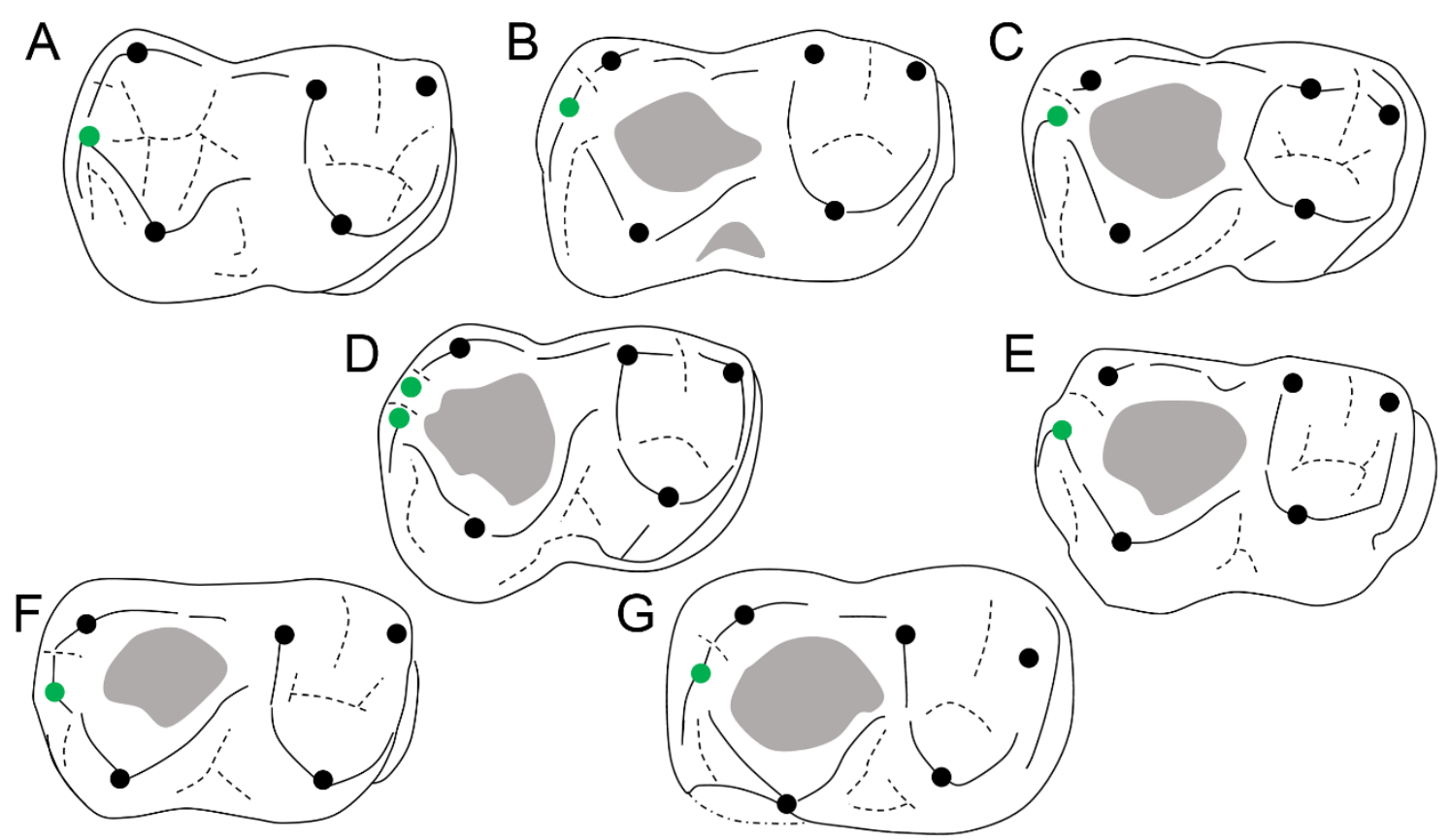

Figure 13. Schematic pattern of grooves and crests of the first lower molar in occlusal view of: A, D. ilicis (USNM 538371, after Rose et al., 2012: fig.51G); B, D. antunesi (SNC 63); C, D. indicus (GU 29, after Kumar et al., 2010: fig.7D, mirror view); D, D. morrisi (holotype, M83071, after Hooker, 2010: fig.47e), E, D. varleti (holotype, MNHN CB 255); F, D. gigasei (IRScNB M 1816, after Smith et al., 1996: pl. 1.2a); G, D. gazini (RI 165). Full lines originating from cuspids represent crests, dotted lines represent grooves, grey surfaces represent the basin of the talonid. The hypoconulid is highlighted in green. Not to scale. 